\title{
Mathematical Modeling of Local Scour at Slender and Wide Bridge Piers
}

\author{
Youssef I. Hafez \\ Royal Commission Yanbu Colleges and Institutes, Yanbu University College, P.O. Box 31387, Yanbu, Saudi Arabia \\ Correspondence should be addressed to Youssef I. Hafez; mohammedy@rcyci.edu.sa
}

Received 11 January 2016; Accepted 12 April 2016

Academic Editor: Robert Spall

Copyright ( 2016 Youssef I. Hafez. This is an open access article distributed under the Creative Commons Attribution License, which permits unrestricted use, distribution, and reproduction in any medium, provided the original work is properly cited.

\begin{abstract}
Most existing equations for predicting local scour at bridge piers suffer from overprediction of the scour depths which results in higher foundation costs. To tackle this problem, a mathematical model for predicting bridge pier scour is developed herein based on an energy balance theory. The present study equation was compared to commonly used bridge scour equations using scour field data in USA. The developed equation has several advantages among which we have the following: it adds to the understanding of the physics of bridge pier scour, is valid for slender and wide piers, does not suffer from overprediction of scour depths, addresses clear water and live bed scour, and includes the effects of various characteristics of the bed material such as specific gravity (or density), porosity, size, and angle of repose. In addition, the developed equation accounts for the debris effect and aids in the design of scour mitigation methods such as collars, side bars, slots, and pier protective piles.
\end{abstract}

\section{Introduction}

According to a comprehensive collection of bridge failure data worldwide gathered by Imhof [1], natural hazard is the main cause of bridge collapse as it amounts to about $30 \%$ of total collected bridge collapse cases. Among the natural hazard listed causes, flooding or scour is responsible worldwide for around $60 \%$ of the collapse cases. The Federal Highway Administration (FHWA) has estimated that $60 \%$ of bridge collapse cases in the USA are due to scour $[2,3]$ and, on average, about 50 to 60 bridges fail each year in the USA [4]. Wardhana and Hadipriono [5] studied 500 failures of bridge structures in the United States between 1989 and 2000 and showed that the most recurrent causes of bridge failures were due to floods, scour, and impacts.

Brandimarte et al. [6] state that scour at bridge crossings is usually the result of the joint effects of three different scour processes (general scour, contraction scour, and local scour at piers) that may occur either independently or simultaneously, whose different origin suggests a different estimate of each individual scour contribution. Local scour usually results from the joint effect of contraction scour, due to the flow velocity increase associated with the reduction of the channel section, and the pier and abutment scour, due to the (local) alteration of the flow field induced by piers and abutments, Graf [7].

A system of vortices develops around a pier when the flow is obstructed by the pier. Brandimarte et al. [6] explain that depending on bridge geometry and flow conditions the system of vortices can be composed of all, any, or none of three individual basic systems acting at the pier: (a) the horse-vortex system at the base of the pier; (b) the wakevortex system downstream of the pier; and (c) the surface roller ahead of the pier. Raudkivi [8], based on experimental observations of flow around piers, states that the horseshoe vortex is a consequence of scour, not the cause of it, although it becomes effective in transporting material away from the scour hole. The horseshoe vortex extends downstream, past the sides of the pier, for a few pier diameters before losing its identity and becoming part of general turbulence. In the scour hole, the horseshoe vortex pushes the maximum downflow velocity still closer to the pier. The downflow acts like a vertical jet eroding a groove in front of the pier. The eroded material is carried around the pier by the combined action of accelerating flow and the spiral motion of the "horseshoe vortex." Melville and Coleman [9] report that the 
wake-vortex system acts like a vacuum cleaner sucking up stream bed material and transporting downstream of the pier the sediment moved by the downward flow and by the horsevortex system.

Fischenich and Landers [11] report many useful observations about scour such as the following: (1) generally, depths of local scour are much higher than general scour or contraction scour depths, often by a factor of ten, (2) the wider the obstruction, the deeper the scour, (3) the ratio of obstruction width to channel width is probably a better measure of scour potential than is the obstruction width alone, (4) the limit on the increase in scour depth with an increase in projected length is when the projected length into the stream to the depth of the approaching flow is 25 , (5) the streamwise length of a structure has no appreciable effect on scour depth for straight sections, (6) an increase in flow depth can increase scour depth by a factor of 2 or greater, (7) scour depth also increases with the velocity of the approach flow, (8) size of bed material may not affect the ultimate or maximum scour but only the time it takes to reach it, (9) structures that cause flow convergence increase scour and vice versa, (10) streamlining structures reduces the strength of horseshoe and wake vortices thus reducing ultimate scour depths, and (11) ice and debris can increase both the local and general (contraction) scour.

To design safe bridges located on waterways under severe flooding conditions, many researchers have developed empirical formulae for predicting bridge pier scour depth. Review of the most-commonly used formulae is given in the next section.

\section{Review of Past Bridge Pier Scour Research}

For more than half a century, a large number of equations have been suggested for estimating bridge pier scour. These equations are mostly empirical formulae which are often based on regression relations of laboratory and/or field scour data. Because the number of these equations is quite large, selection of the best performing equations is quite a difficult task. Comparison studies of scour formulae may help in selecting those formulae which have satisfactory performance.

There have been several studies in which comparisons were made of the performance of scour prediction equations. Mohamed et al. [12] selected four commonly used formulae for the validation process using both laboratory and field data. The selected equations were the Colorado State University (CSU), Melville and Sutherland, Jain and Fischer, and Laursen and Toch formulae. The experimental data were obtained from a laboratory model study at University Putra Malaysia while field data were obtained from 14 bridges from which 11 were in Pakistan, 2 in Canada, and 1 in India. They showed that the Laursen and Toch and the CSU formulae appeared to give a reasonable estimate when compared to laboratory and field data. The Melville and Sutherland and Jain and Fischer formulae appeared to overpredict the depth of the scour. The maximum absolute error between the field scour depths and the computed scour depths using the CSU formula was $3.15 \mathrm{~m}$, while the minimum absolute error was $0.14 \mathrm{~m}$.

Mueller and Wagner [13] in a detailed study used 266 pier scour measurements to investigate the performance of 27 pier scour equations. They reported that some equations (Ahmad, Breusers-Hancu, Chilate, Inglis-Poona I, Mellive and Sutherland, and Shen-Maza) show trends away from the line of equality (when graphing computed scour depths versus measured scour depths), indicating that those equations do not properly represent the processes responsible for local pier scour in the field. Several equations (Arkansas, BlenchInglis I, Blench-Inglis II, Froehlich with no safety factor, Shen, and Simplified Chinese) underpredict the depth of scour for a significant number of observations and are not good candidates for design equations. The other equations have some trend along the line of equality with few underpredictions, but they display a broad scatter of data and often do not accurately predict the observed scour. Mueller and Wagner [13] stated that ranking the performance of scour prediction equations is difficult because of the tradeoff between accuracy and underpredictions. If only accuracy is considered, the sum of squared errors can be used to evaluate the equations' performance. This statistic shows the Froehlich equation (no safety factor) to be the most accurate; however, the Froehlich equation is a regression expression and underpredicted the depth of scour for 129 of 266 field observations. If the smallest number of underpredictions is used, the Froehlich Design equation is the best because it underestimated only four observations. The Froehlich Design equation, however, ranked 19th based on the sum of squared errors criteria.

The author herein agrees with Mueller and Wagner [13] opinion that the magnitude of underpredictions is just as important (if not more important than) as the number of underpredictions; thus the sum of squared errors for those observations that were underpredicted is another important factor that should be considered. Mueller and Wagner [13] concluded that no single equation is conclusively better than the rest, but the top six equations for design purposes generally appear to be the Froehlich Design, HEC-18-K4, HEC-18-K4Mu, HEC-18-K4-Mo (>2 mm), Mississippi, and HEC-18 equations. The comparison of the scour depths predicted from these equations with measured scour depths shows processes in the field data not accurately accounted for in these equations. They report that the methodology for computing scour at bridges published in HEC-18 provides estimates that are generally conservative, in that the depth of scour is usually overpredicted.

Ghorbani [22] used data for 6 bridges on 3 rivers in Fars Province, Iran, to test several scour formulae. A comparison of scour equations with field measurements revealed that the Hanco, CSU, Viega, and Neill equations exhibited rather good agreement with field data; however, Indian and Inglis equations overestimated scour depth.

Lu et al. [23] collected field data, at the Si-Lo Bridge in the Lower Choshui River, Taiwan, comprising both general scour and total scour depths. They developed scour component separation methodology from which they obtained local pier scour. They used ten commonly used equilibrium pier scour equations, Neill [14], Shen et al. [15], Coleman [24], Breusers 
et al. [17], Jain and Fischers [25], Chiew and Melville [26], Froehlich [19], HEC-18 [27], Melville and Coleman [9], and Sheppard and Miller Jr. [28], to calculate local pier scour depths under peak flood conditions. They found that most formulae tend to overestimate the local scour depths.

Beg [29] selected fourteen commonly used and cited bridge pier scour predictors for testing against published laboratory and field data obtained from various sources and his experimental data. The study reveals that the predictors of Laursen and Toch and Jain and Fischer produce a reasonable estimate.

Recently, Sheppard et al. [21] used 569 laboratory and 928 field data for evaluation of existing equations for local scour at bridge piers. They started with twenty-three of the more recent and commonly used equilibrium scour equations for cohesionless sediments. Quality-control screening methods applied to both the data and the equations resulted in 441 laboratory and 791 field data and 17 predictive equations/methods. In their opinion, unknown maturity of the scour hole at the time of measurement for the field data resulted in use of field data only to evaluate underpredictions by the equations. They found that the regime equations of Inglis [30], Ahmad [31], and Chitale [32] yield negative scour depths in some cases, the Coleman [24] equation yields an unrealistic trend with increasing pier size, and Inglis [30], Ahmad [31], Chitale [32], Hancu [33], and Shen et al. [15] predict unreasonably high normalized scour depths. They also found that the predictive methods improve in accuracy over the years with those developed in recent years demonstrating the best performance. Sheppard et al. [21] concluded that Sheppard/Melville [21] method was found to be the most accurate method of those tested and is recommended for use in bridge design.

Gaudio et al. [34] state that existing scour equations were derived in small scale conditions and therefore the application to practical cases is uncertain. They selected six design equations, namely, Breusers et al. [17], Jain and Fischer [18], Froehlich [19], Kothyari et al. [35], Melville [20], and FHWA (HEC-18, [36]), for testing using synthetic data (obtained from Monte Carlo simulation technique) and the original field data set for uniform sediments. They found that the selected equations performance is not satisfactory when predicting maximum scour depth at equilibrium conditions.

The following review presents selected pier scour equations based on the foregoing review of past investigations. These equations represent scour research efforts spanned over nearly 50 years. These equations include the most influencing scour variables based on either laboratory or field data and are thought to perform at a satisfactory level.

Almost fifty years ago, Neill [14] used Laursen and Toch's [37] design curve to obtain the following explicit formula for the scour depth:

$$
\frac{D_{s}}{b}=1.5\left(\frac{H}{b}\right)^{0.3},
$$

where $D_{s}$ is the equilibrium scour depth, $b$ is the obstruction width (or pier width), and $H$ is the approach water depth. This equation does not include the Froude number or in other words the velocity of the attacking stream.
Shen et al. [15] used the Froude number in their scour depth prediction in addition to the pier width as

$$
\frac{D_{s}}{b}=3.4\left(F_{r}\right)^{2 / 3}\left(\frac{H}{b}\right)^{1 / 3},
$$

where $F_{r}$ is the Froude number and the other variables are as defined before.

The Colorado State University or CSU formula [16] is developed as a best fit to the data (laboratory) available at the time. The formula is given as

$$
\frac{D_{s}}{H}=2.2\left(\frac{b}{H}\right)^{0.65}\left(F_{r}\right)^{0.43} .
$$

The CSU [16] formula is similar in form to Shen et al. [15] equation. Later on correction factors were added for effects of flow angle of attack, pier shape, and bed sediment conditions.

Breusers et al. [17] investigated clear water and live bed scour conditions. They included the critical velocity for incipient motion as follows:

$$
\frac{D_{s}}{b}=2\left\{2 \frac{V}{V_{c}}-1\right\} \tanh \left(\frac{H}{b}\right),
$$

where $V$ is the average approach stream flow velocity and $V_{c}$ is the critical velocity for sediment motion computed with the Neill [38] equation in SI units as

$$
V_{c}=31.08 \theta_{S}^{1 / 2} H^{1 / 6} D_{50}^{1 / 3},
$$

where the Shields mobility parameter, $\theta_{S}$, can be computed based on sediment size as given in Mueller and Wagner (p. 20 in [13]), and $D_{50}$ is the median grain size. Therefore this equation includes implicitly the sediment size through the critical velocity.

Jain and Fischer [18] developed a set of equations based on laboratory data. For $\left(F_{r}-F_{c}\right)>0.2$, in live bed conditions the formula reads as

$$
\frac{D_{s}}{b}=2.0\left(F_{r}-F_{c}\right)^{0.25}\left(\frac{H}{b}\right)^{0.5},
$$

where $F_{r}=V /(g H)^{0.5}$ and $F_{c}=V_{c} /(g H)^{0.5}$ are the Froude number and critical Froude number, respectively. For $\left(F_{r}-\right.$ $\left.F_{c}\right)<0$ in clear water conditions, the formula is

$$
\frac{D_{s}}{b}=1.84\left(F_{r}\right)^{0.25}\left(\frac{H}{b}\right)^{0.3} \text {. }
$$

For $0<\left(F_{r}-F_{c}\right)<0.2$ the larger value which is obtained from (6) and (7) is to be taken. This formula provides separate expressions for each of the clear and live bed conditions.

Froehlich's [19] design equation for live bed scour at bridge crossings based on field data of about 170 live bed scour measurements is

$$
D_{s}=0.32 \phi_{1}\left(b^{\prime}\right)^{0.62}(H)^{0.47} F_{r}^{0.22} D_{50}^{-0.09}+b,
$$

where $b^{\prime}$ is projected pier width with respect to the direction of the flow and $\phi_{1}$ is coefficient based on the shape of the 


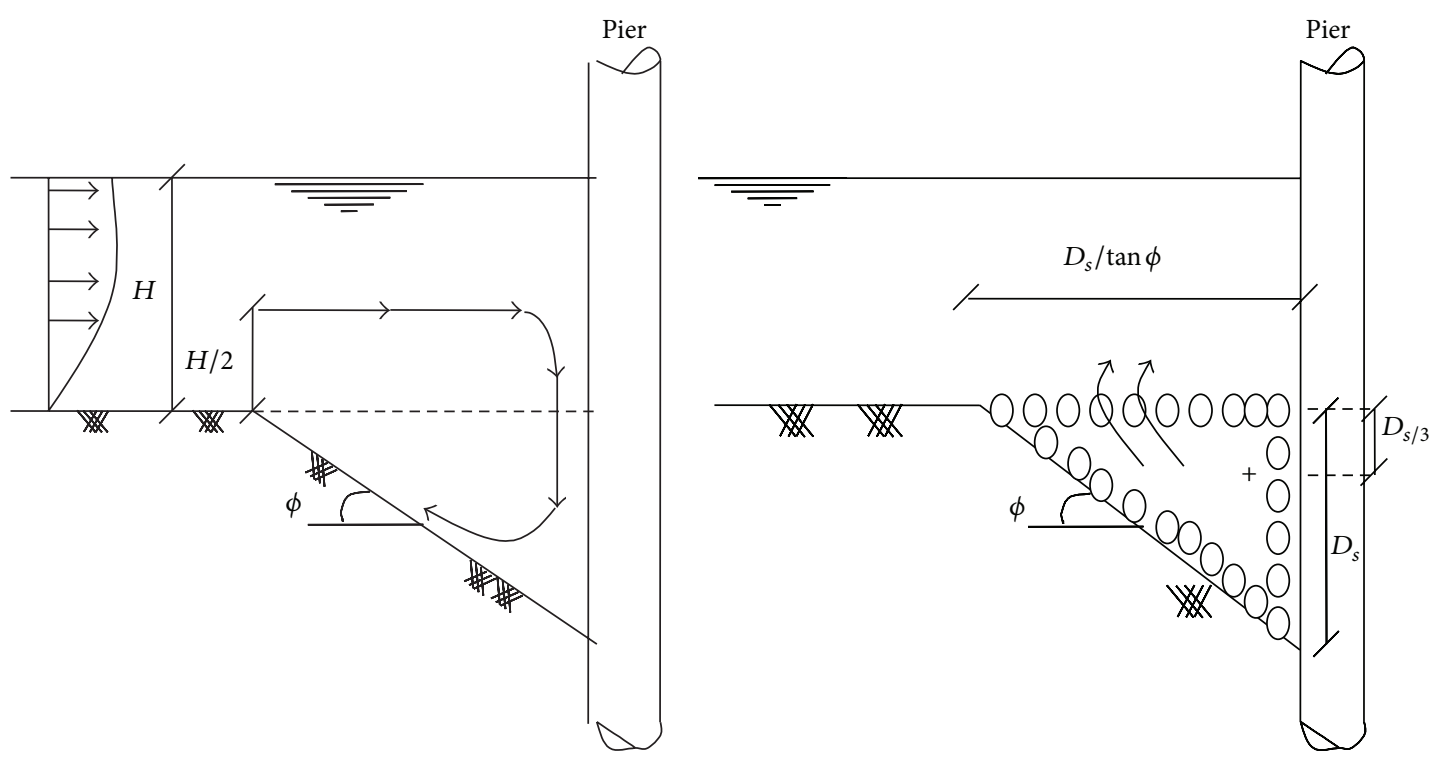

(a)

(b)

FIGURE 1: Schematic diagrams of flow at a bridge pier in the symmetry plane, (a) longitudinal flow transformation into downflow, (b) scour hole shape, after Hafez [10].

pier nose. This equation includes a safety factor $(+b)$ added to the right hand side of (8) that accounts for contraction scour in most cases and this equation will be called herein Froehlich equation with safety. To test this formula as a prediction formula, this factor is omitted as in (9), as only local bridge pier scour is considered. Equation (9) is named herein Froehlich's local scour equation with no safety:

$$
D_{s}=0.32 \phi_{1}\left(b^{\prime}\right)^{0.62}(H)^{0.47} F_{r}^{0.22} D_{50}^{-0.09} \text {. }
$$

Melville [20] formula for clear water and live bed scour conditions is

$$
D_{s}=K_{h b} K_{l} K_{d} K_{S} K_{\theta} K_{G},
$$

where $K_{h b}, K_{l}, K_{d}, K_{S}, K_{\theta}$, and $K_{G}$ are coefficients taking into account the depth scale, the flow intensity, the sediment size, pier shape, pier alignment, and channel geometry effects on scour depth, respectively.

Among the few analytically based equations is the one developed by Hafez [10] based on his energy balance theory. The energy balance theory assumes that at the equilibrium geometry of the scour hole the work done by the attacking fluid flow upstream of the bridge pier is equal to the work done in removing the volume of the scoured bed material out of the scour hole. In other words the energy contained in the fluid flow attacking the bridge pier is converted to an energy consumed in removing or transporting the bed material, thus forming a scour hole. When all the flow energy is consumed in transporting the sediment out of the scour hole, scour ceases and the scour hole becomes stable and at its maximum or equilibrium scour depth.

The following assumptions or postulates were made in Hafez [10] and repeated here for completeness and for comparison with the present study: (1) the shape of the upstream slope of the scour hole in the stagnation vertical symmetry plane is linear; that is, the scour hole has a triangular shape, Figure 1(a); (2) the equilibrium scour hole has an upstream slope that is equal to the angle of repose of the bed material; (3) the scour hole is formed due to the conversion of the horizontal momentum of flow coming to the pier to downward or vertical momentum attacking the bed surface, Figure 1(a); (4) the downflow component is responsible for transferring the momentum of the attacking flow to the bed material particles which are raised or transported to the original bed level and carried away by the horseshoe vortices; (5) the analysis is done for a jet thickness of one sediment particle diameter (also unit width) which is similar to working in the stagnation symmetry plane (two-dimensional analysis); (6) the resultant horizontal force of the attacking flow travels downward a distance equal to half the water depth plus half the scour depth; and (7) the volume of the scoured bed which is assumed to be triangular in shape and as a mega sediment particle is moved to the original bed level out of the scour hole. Its center of mass is located at a distance equal to $1 / 3$ of the scour depth, Figure 1(b). After using the above postulates the following equation was obtained by Hafez [10] as

$$
\begin{aligned}
\left(\frac{D_{s}}{H}\right)^{3}= & \left(\frac{3 \tan \phi}{\left(S_{G}-1\right)(1-\theta)}\right)\left(\frac{1}{(1-b / B)^{2}}\right)\left(\frac{\eta^{2} V_{x}^{2}}{g H}\right) \\
& \cdot\left(1+\frac{D_{s}}{H}\right),
\end{aligned}
$$

where $D_{s}$ is the maximum or equilibrium scour depth, $H$ is the water depth, $\phi$ is the upstream slope of the scour hole in the symmetry plane (assumed to be equal to the bed material angle of repose), $\theta$ is the bed material porosity, $S_{G}$ is the bed material specific gravity, $b$ is the pier width, $B$ is the 
channel width in case of one pier or the bridge span or pier centerline-to-centerline distance in case of multiple piers, $\eta$ is a transfer coefficient of the horizontal momentum into a vertical momentum in the downward direction, $V_{x}$ is the local longitudinal flow velocity just upstream of the pier of the jet attacking the bridge in the direction normal to the pier ( $V_{x}$ is assumed to be equal to the approach average velocity, $V$, in case of no data), and $g$ is the gravitational acceleration.

Equation (11) expresses the normalized equilibrium bridge pier scour depth in terms of the local velocity, local flow depth, bed material specific gravity and porosity, bed material angle of repose, pier width over channel width ratio, and a momentum transfer coefficient. Equation (11) is a cubic nonlinear equation. Though a closed form expression for the scour depth could be obtained, a few iterations could be used to solve iteratively for the scour depth. Hafez [10] tried to justify why his equation does not explicitly contain the pier width and bed material size. He used arguments from Fischenich and Landers [11] that the ratio of obstruction width to channel width is a better measure of scour than is the obstruction width alone and that the sediment size may not affect maximum scour but only the time it takes to reach it. However, these deficiencies might be the cause for the unpopularity of this equation.

Sheppard et al. [21] develop Sheppard/Melville equation by melding the equations of Sheppard and Miller Jr. [28] and Melville [20] with slight modification to form a new equation. The resulting equation for the normalized scour depth $D_{s} / b^{*}$ is

$$
\begin{aligned}
\frac{D_{s}}{b^{*}} & =2.5 f_{1} f_{2} f_{3}, \quad \text { for } 0.4 \leq \frac{V}{V_{c}}<1.0, \\
\frac{D_{s}}{b^{*}} & =f_{1}\left[2.2\left(\frac{V / V_{c}-1}{V_{1 p} / V_{c}-1}\right)\right. \\
& \left.+2.5 f_{3}\left(\frac{V_{1 p} / V_{c}-V / V_{c}}{V_{1 p} / V_{c}-1}\right)\right], \\
\frac{D_{s}}{b^{*}} & =2.2 f_{1}, \quad \text { for } \frac{V}{V_{c}}>\frac{V_{1 p}}{V_{c}}, \\
f_{1} & =\tanh \left[\left(\frac{H}{b^{*}}\right)^{0.4}\right], \\
f_{2} & =\left\{1-1.2\left[\ln \left(\frac{V}{V_{c}}\right)\right]^{2}\right\}, \frac{V_{1 p}}{V_{c}}, \\
V_{1 p 2} & =0.6 \sqrt{g H}, \quad\left(b^{*} / D_{50}\right) \\
f_{3} & =\left[\frac{1.0}{0.4\left(b^{*} / D_{50}\right)^{1.2}+10.6\left(b^{*} / D_{50}\right)^{-0.13}}\right],
\end{aligned}
$$

$$
\begin{array}{ll}
V_{1 p}=V_{1 p 1}, & \text { for } V_{1 p 1} \geq V_{1 p 2} \\
V_{1 p}=V_{1 p 2}, & \text { for } V_{1 p 2}<V_{1 p 1}
\end{array}
$$

where $b^{*}$ is effective diameter of the pier $=K_{s} a_{p} ; K_{s}$ is shape factor; and $a_{p}$ is projected width of the pier. For circular piers, $K_{s}=1$, while for rectangular piers

$$
K_{s}=0.86+0.97\left(\left|\alpha-\frac{\pi}{4}\right|\right)^{4}
$$

where $\alpha$ is flow skew angle in radians. Sheppard et al. [21] estimated the sediment critical velocity, $V_{c}$, from a set of equations describing the Shields [39] diagram. Their scour equation is actually a set of equations that contains 14 equations to obtain scour depth values which makes it difficult for use.

From the foregoing review of past bridge pier scour equations which are based on laboratory and field data, the following can be stated. These empirical equations are based on dimensional analysis and regression techniques using laboratory and/or field data but they do not explain the physics of the scour phenomenon nor the exact way through which each variable is influencing the scour mechanism. These equations tell only the magnitude of importance of the isolated effect of each variable and seem to be as a black box. Therefore, there is lots of empiricism inherited in these equations through adjustment or correction coefficients. Since these equations are derived from laboratory and/or field data, there is also some bias in testing these equations using the same laboratory and/or field data.

Effects of the bed material specific gravity or equivalently density, porosity, and angle of repose are not directly addressed in existing scour equations except through correction factors. Raudkivi [8] reported that "the upstream part of the scour hole develops rapidly and has the shape of a frustum of an inverted cone with slope equal to the angle of repose of the bed material under erosion conditions."

The fact that the upstream slope of the scour hole is related to the angle of repose indicates that the angle of repose affects the depth of scour, yet no scour formula contains the angle of repose as a scour influencing variable. In most scour depth equations cited in the literature, the pier width has a directeffect on scour depth; the wider the pier width the deeper the scour. Therefore, for obstructions having large widths, most existing scour equations would predict considerably larger scour depths than would be practically existing which leads to the wide pier problem. Overprediction by these equations of bridge pier scour remains the most unsatisfactory aspect which results in higher foundation costs that might not be necessary. In the following there is an attempt to overcome most of the shortcomings experienced in past methods.

\section{The Present Study Equation}

An analytically based equation is developed herein based on the mathematical model for the energy balance theory initiated by Hafez [10]. The present study adopts the same 


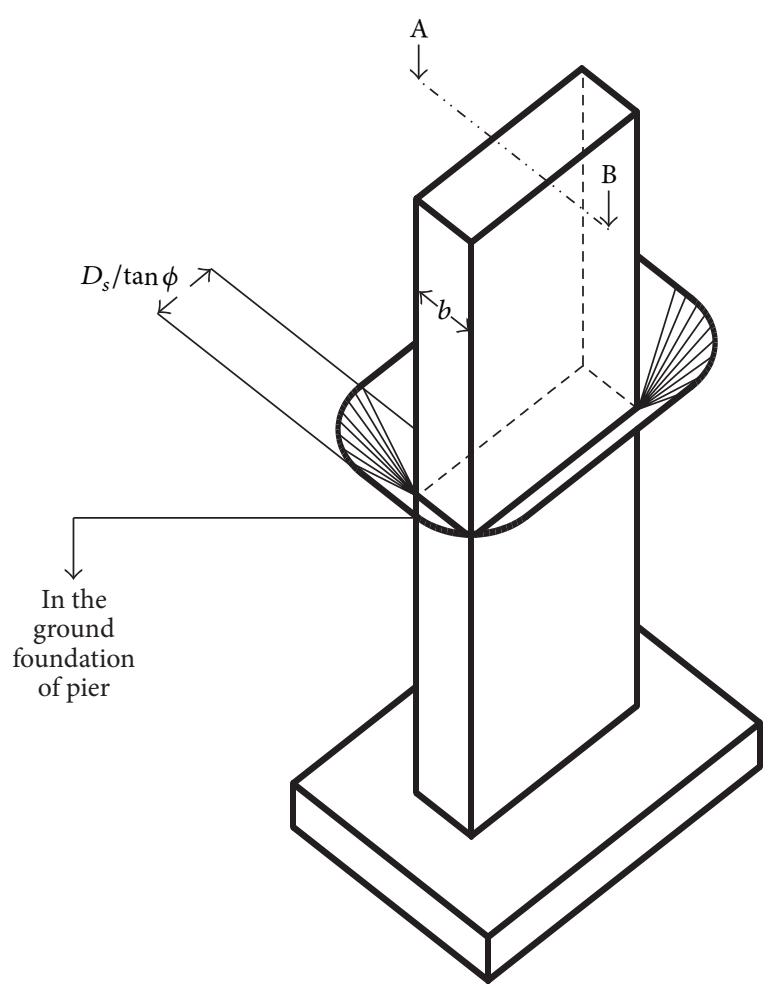

(a)

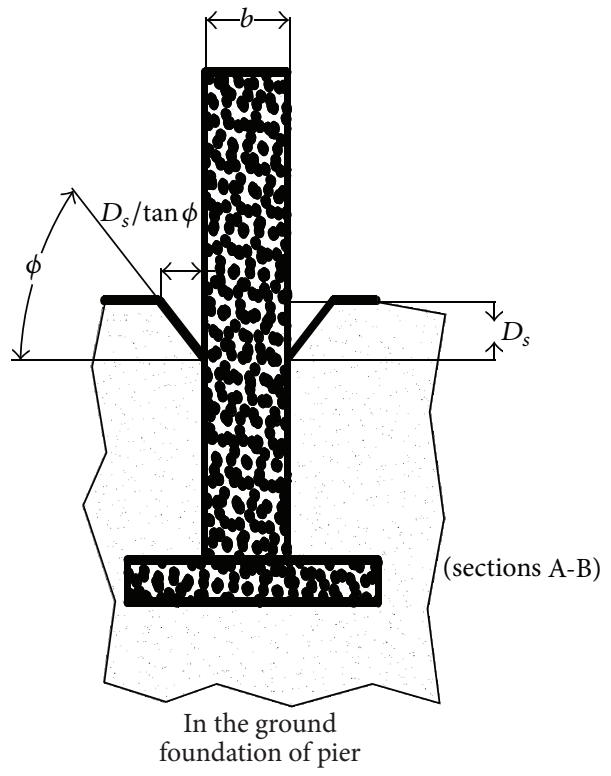

(b)

FIGURE 2: Schematic diagram of the three-dimensional scour hole (a) and front view (b).

energy concept used by Hafez [10] with two significant additions. As will be seen later, although Hafez [10] equation improves scour prediction compared to other scour prediction equations, it does not include explicitly the effects of the pier width and the bed material mean diameter. To show how this is done and for the sake of completeness, the energy balance theory is reexplained here.

The energy balance theory assumes that at the equilibrium geometry of the scour hole the work done by the attacking fluid flow upstream of a bridge pier is transformed to work done in removing the volume of the scoured bed material out of the scour hole. When all the flow energy is consumed in transporting the bed material out of the scour hole, the scour ceases and the scour hole becomes stable and at its maximum scour depth. Hafez [10] made a vertical two-dimensional analysis in which the scour hole was analyzed in its symmetry plane. Therefore, width of the pier did not explicitly appear in his equation except in the velocity amplification factor $(1-b / B)$, where $b$ is the pier width and $B$ is the channel width or pier-to-pier distance, resulting from the reduction in flow width and consequently increase in velocity. However, this factor might contribute to the contraction scour rather than to the local scour. In the present study, the three-dimensional aspects of the scour hole are fully considered which will enable a more general expression of scour prediction for two cases, namely, slender (normal) and wide piers.
The following assumptions are made:

(1) The analysis considered here is three-dimensional which deals with the volume of the scour hole upstream of the bridge pier as a mega sediment particle. The analysis is done for rectangular piers (for circular and other pier shapes correction factors cited in previous studies can be used).

(2) The shape of the three-dimensional scour hole upstream of the bridge pier consists of basically three parts as shown in Figures 2 and 3, the middle part is a prism with horizontal axis and triangular cross section, and the side parts are two identical conical solids with vertical axis and their volume equal to a quarter of a whole cone. Each cone lies at one end of the prism as seen in Figures 2 and 3. The prism has a height equal to the pier width. The cross section of the prism and the quartile-cones is a right triangle. The hypotenuse of this right triangle constitutes the upstream slope of the scour hole and is assumed to be linear.

(3) The equilibrium scour hole has an upstream slope (hypotenuse) that is assumed to be equal to the angle of repose of the bed material.

(4) The scour hole upstream of the pier is formed due to the conversion of the horizontal jet of the flow coming 


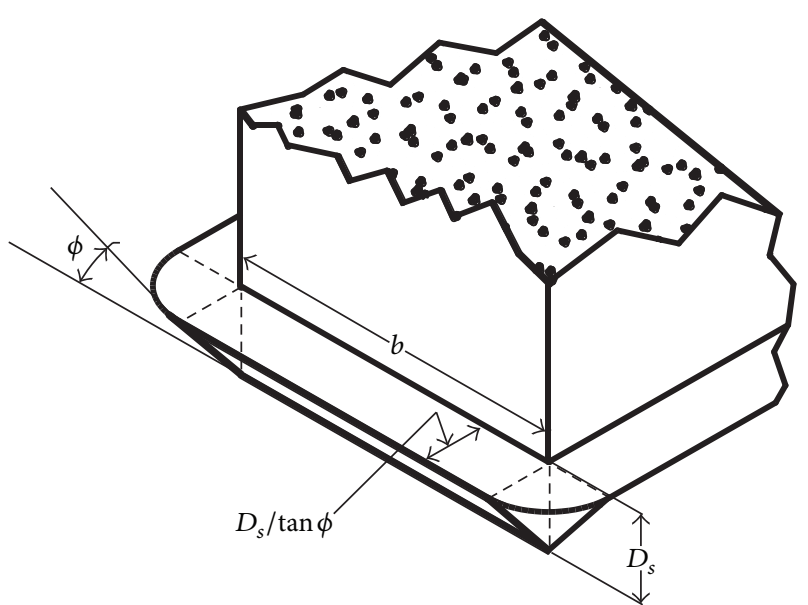

FIGURE 3: Closer view to the upstream part of the three-dimensional scour hole.

to the pier to a downward or vertical jet attacking the stream bed surface as shown in Figure 1(a).

(5) The downflow component is responsible for transferring the momentum of the attacking flow to the bed material particles which are raised or transported to the original bed level and carried away by the horseshoe vortices and the flow between the piers.

(6) The horizontal forces of the attacking flow have their resultant force acting at 0.7 of the water depth above the bed level; see the appendix. Then after bending vertically downward, the resultant force acts at half the scour hole and travels inside the scour hole a distance equal to half the scour depth. Thus, the total distance that the resultant force travels downward under the gravitational field is 0.7 of the channel depth plus half the scour depth $D_{s}$. Gravity exerts work on this jet and this work by gravity due to downward motion is the source for the scour energy.

(7) The volume of the scoured bed is moved to the original bed level out of the scour hole. Its center of mass is assumed at a distance equal to $1 / 3$ of the scour depth, Figure 1(b).

(8) The analysis is done under steady flow conditions.

Basic fluid mechanics teaches, Roberson and Crowe [40], that the flow hydrodynamic momentum force can be expressed as $\rho Q V$, where $\rho$ is the fluid density, $Q$ is the flow discharge, and $V$ is the flow longitudinal velocity. In the case of flow blocked by bridge piers this force can be assumed as $F_{b}=$ $\rho Q_{b} V_{x}$, where $F_{b}$ is the blocked flow force, $Q_{b}$ is the blocked flow discharge by the pier or obstruction, and $V_{x}$ is the flow velocity (time average or mean) just upstream of the pier. That part of the blocked flow discharge $\left(Q_{b}=V_{x} H b\right.$, where $H$ is the local flow depth and $b$ is the pier width) that spreads across the width of the pier is assumed to be the effective flow responsible for pier scour. The blocked flow force on the average is thus given as

$$
F_{b}=\rho V_{x}^{2} H b .
$$

This average force moves downward a distance of $(0.7 \mathrm{H}+$ $D_{s} / 2$ ) according to assumption (6) above that is 0.7 of the channel water depth plus half the scour hole depth. Hafez [10], on the other hand, took this distance as $\left(H / 2+D_{s} / 2\right)$. It is assumed that the horizontal water jet upstream of the bridge pier consists of thin water tubes or filaments which upon approaching the bridge pier bend downward vertically. The surface tube will hit the bridge pier and then bends downward while being attached to the pier surface and travels a distance equal to the water depth plus a distance equal to the full depth of the scour hole $\left(D_{s}\right)$ reaching its deepest point. The tube attached to the river bed has almost zero velocity and will just touch the outer edge of the scour hole, that is, traveling a downward distance equal to zero. The water tubes between the surface tube and the bed tube will squeeze themselves after bending down and travel a vertical downward distance in the range between zero and $D_{s}$. The average distance thus traveled downward by all tubes inside the scour hole will be $D_{s} / 2$. In conclusion, if only considering the resultant or average water force which is at height $0.7 \mathrm{H}$ it will bend down this distance till it reaches the original river bed (scour hole upper boundary) then it travels downward a distance equal to $D_{s} / 2$. Thus the total distance will be $0.7 H+D_{s} / 2$.

From basic mechanics, the work done by a force is given as the product of the force and the distance along the force that this force travels. Therefore, the work done $\left(W_{\text {in }}\right)$ by gravity on the fluid flow of the jet coming upstream of the bridge pier can now be expressed as

$$
W_{\text {in }}=\rho V_{x}^{2} H b \eta^{2}\left(0.7 H+\frac{D_{s}}{2}\right) .
$$

A momentum transfer coefficient, $\eta^{2}$, is introduced in (15) to express the conversion of the longitudinal momentum (energy) to vertical momentum (energy) that is to represent the efficiency of momentum or energy transfer. As the momentum force is proportional to the square of the velocity as in (14), the factor $\eta$ is squared in (15). At extreme flooding conditions and high velocity streams $\eta$ might be taken as unity indicating complete transfer of the longitudinal momentum into vertical downward momentum or in other words complete transformation of the horizontal velocity into vertical downward velocity.

Now the volume, Vol., of the scour hole at its maximum or equilibrium condition is according to Figure 3 given by

$$
\begin{aligned}
\text { Vol. } & =2\left\{\frac{1}{4} \frac{\pi}{3}\left(\frac{D_{s}}{\tan \phi}\right)^{2} D_{s}\right\}+\frac{1}{2} b\left(\frac{D_{s}}{\tan \phi}\right) D_{s} \\
& =\left(\frac{D_{s}^{2}}{2 \tan \phi}\right)\left(\frac{\pi}{3} \frac{D_{s}}{\tan \phi}+b\right),
\end{aligned}
$$

where $\phi$ is the upstream slope of the scour hole. The first term on the middle part of (16) represents the volume of a quarter of a cone (with height $D_{s}$ and radius of the base $D_{s} / \tan \varphi$ ) 
multiplied by 2 to represent the two conical quarters. The second term in the middle of (16) represents the volume of a prism with height $b$ and triangular cross section. The height of this triangle is the scour depth $D_{s}$ and the base of the triangle is $D_{s} / \tan \varphi$.

The bed material which was in the scour hole was filled with water through a porosity coefficient $\theta$ (usually taken as 0.4 for sands). Therefore the amount of the bed material that was in the equilibrium scour hole becomes \{Vol. times (1 $\theta)\}$. Then, the submerged weight of this material becomes

$$
\left\{\frac{1}{2} \frac{\pi}{3}\left(\frac{D_{s}}{\tan \phi}\right)^{2} D_{s}+\frac{1}{2} b \frac{D_{s}}{\tan \phi} D_{s}\right\}(1-\theta)\left(\gamma_{s}-\gamma\right),
$$

where $\gamma_{s}$ is the bed material unit weight and $\gamma$ is the fluid unit weight. Now this weight force can be assumed to act at the scour hole-center of mass which is located at $D_{s} / 3$ below the original bed level, as seen in Figure 1(b). From basic mechanics, the work done to remove this weight force is equal to the weight force times the displaced distance $\left(D_{s} / 3\right)$. Therefore, the work done $\left(W_{\text {out }}\right)$ in removing the bed material out from the scour hole is

$$
\begin{aligned}
W_{\text {out }}= & \left\{\frac{1}{2} \frac{\pi}{3}\left(\frac{D_{s}}{\tan \phi}\right)^{2} D_{s}+\frac{1}{2} b \frac{D_{s}}{\tan \phi} D_{s}\right\}(1-\theta) \\
& \cdot\left(\gamma_{s}-\gamma\right) \frac{D_{s}}{3} .
\end{aligned}
$$

Equation (18) can be rearranged and written as

$$
W_{\text {out }}=\rho g\left(S_{G}-1\right)(1-\theta) \frac{D_{s}^{3}}{6 \tan \phi}\left\{\frac{\pi}{3} \frac{D_{s}}{\tan \phi}+b\right\} .
$$

Here $S_{G}$ is the sediment specific gravity and $g$ is the gravitational acceleration.

Under assumptions (4) and (5) of equal work at the equilibrium conditions, that is, $W_{\text {in }}=W_{\text {out }}$, (15) and (19) can be made equal which yields

$$
\begin{aligned}
\rho g & \left(S_{G}-1\right)(1-\theta) \frac{D_{s}^{3}}{6 \tan \phi}\left\{\frac{\pi}{3} \frac{D_{s}}{\tan \phi}+b\right\} \\
& =\rho V_{x}^{2} H d \eta^{2}\left(0.7 H+\frac{D_{s}}{2}\right) .
\end{aligned}
$$

Dividing both sides of (20) by $H^{3}$ and after some manipulations, (20) becomes

$$
\begin{aligned}
\left(\frac{D_{s}}{H}\right)^{3}= & \left(\frac{3 \tan \phi}{\left(S_{G}-1\right)(1-\theta)}\right) \\
& \cdot\left(\frac{1}{\left((\pi / 3 \tan \phi)\left(D_{s} / b\right)+1\right)}\right)\left(\frac{\eta^{2} V_{x}^{2}}{g H}\right) \\
& \cdot\left(1.4+\frac{D_{s}}{H}\right) .
\end{aligned}
$$

Equation (21) expresses the equilibrium bridge pier scour depth in terms of the local velocity, the local flow depth, various bed material characteristics such as specific gravity, porosity and angle of repose, the pier width, and a momentum transfer coefficient. The square of the Froude number can be made to appear in the third term in the right side of (21). On the right hand side of (21) the first bracketed term represents the bed material properties (angle of repose, specific weight, and porosity), the second bracketed term represents the pier width effects, the third bracketed term represents effects of the local velocity and flow depth (or Froude number), and the fourth bracketed term represents the nonlinear effects. Equation (21) has the advantage of explaining the physics of bridge pier scour in a direct way by relating the scour influencing variables to the scour depth and flow hydrodynamics to scour and most of all is valid for both slender (normal) and wide piers. If $b \rightarrow 0$ (slender or normal piers) in (21), then $D_{s} \rightarrow 0$ as well. On the other hand if $b \rightarrow \infty$ (wide piers) then the second term in brackets on the right hand side of $(21) \rightarrow 1$ and (21) becomes

$$
\left(\frac{D_{s}}{H}\right)^{3}=\left(\frac{3 \tan \phi}{\left(S_{G}-1\right)(1-\theta)}\right)\left(\frac{\eta^{2} V_{x}^{2}}{g H}\right)\left(1.4+\frac{D_{s}}{H}\right) .
$$

Equation (22) is nearly the same equation as that given by Hafez [10] in which two-dimensional analysis was made to the scour hole. If the resultant jet force is assumed to act at half the water depth as was assumed by Hafez [10], (22) would be similar to that of Hafez [10], (11), with the 1.4 term in the last bracket replaced by 1.0. In addition, in this case very little or no flow contraction occurs and the width obstruction ratio which appeared in Hafez [10] equation, (11), can be made to disappear from the equation. Therefore, (22) can be considered to hold for wide piers $(b \rightarrow \infty)$ while (21) covers all ranges of pier width, whether slender (normal) or wide piers. In this way the wide pier problem is solved herein analytically.

Equation (21) is a cubic nonlinear equation as in the case of the equation of Hafez [10]. The nonlinearity is a unique feature which expresses the interrelationship among all the variables appearing in the equation and the dependence of the scour geometry on the flow conditions and vice versa. In a nonlinear system $[A(x)]\{x\}=\{R\}$, the coefficient or stiffness matrix, $[A(x)]$, being nonlinear means that it depends on the solution vector $\{x\}$ while the solution vector depends on it also. The coefficient matrix represents the system properties or resistance to change. Applying this concept to (21) indicates that the scour hole geometry including the scour depth depends on flow energy and also the flow energy depends on the scour depth. This last statement can be seen in (15) which expresses the flow energy or work; the deeper the scour hole depth the more the vertical downward distance which leads to increase in the flow energy.

Though a closed form expression for the scour depth could be obtained, a few iterations could be used instead to solve for the scour depth. In the first iteration, $D_{s}$ is assumed to be zero in the fourth bracketed term in the right hand side of (21) from which $D_{s}$ on the left hand side can be evaluated. The calculated value of $D_{s}$ from the first iteration is used in the second iteration to update the right hand side and a new value for $D_{s}$ on the left hand side can be 
obtained. This process is repeated until $D_{s}$ on both sides are close to each other within a specified tolerance. Usually 3 or 4 iterations are sufficient to obtain $D_{s}$ within tolerance of $0.001 \mathrm{~m}$. A FORTRAN computer code was developed to read the scour input data and calculate the pier scour depths from the present study equation and from all the cited equations.

The inclusion of the angle of repose of the bed material in (21) provides the way by which the mean sediment diameter influences the scour process. This can be done through utilizing the relation between the bed material angle of repose and particle size as suggested by Simon and Senturk [41]. Their experiments reveal that the angle of repose decreases with an increase in size until a minimum is reached at particle size of $2.4 \mathrm{~mm}$, at which time the angle of repose increases again. The graphical relation between the angle of repose and particle size can be written as

$$
\begin{array}{ll}
\tan \phi=-0.4120 \log _{10} d+0.7060, & \text { for } d \leq 2.4 \mathrm{~mm}, \\
\tan \phi=+0.3226 \log _{10} d+0.4274, & \text { for } d>2.4 \mathrm{~mm},
\end{array}
$$

where $d$ is the sediment particle size in $\mathrm{mm}$. The mean sediment diameter $D_{50}$ can be substituted for $d$ in (23), and the resulting value of $\tan \phi$ is substituted in (21). Thus, (21) includes the effect of both the sediment size and the pier width which were not included in (11) by Hafez [10].

\section{Description of the Field Data}

Mueller and Wagner [13] reported that laboratory research has dominated the field of local scour at bridge piers but such research is limited by the range of hydraulic conditions typically tested and is conducted under steady flow conditions with uniform bed material. They further stated that relations from laboratory research have not been adequately verified by use of field data. In their opinion, analysis of bridge pier scour field data is more complicated than analysis of laboratory data because in the field all explanatory variables have the potential to vary at the same time while in laboratory often a specific variable is changed while keeping other variables constants. Since laboratory experiments for bridge pier scour have often simplified conditions and scale effects, use of field data is adopted in this study to test the performance of the developed equation along with the other equations which are reviewed herein. The intention is not to give a detailed study that compares the performance of the most widely used scour prediction equations but rather is to show how a theoretically developed equation is able to explain several aspects of the scour phenomenon in addition to being comparable to existing equations.

Sheppard et al. [21] state that potential scale effects exist when using laboratory results for prototype piers and that flow regimes are usually different between model and prototype resulting in differences in the relative magnitudes of the forces involved. They confirm that this is particularly true for such complex mechanisms as sediment transport and scour. In their opinion, field studies have the advantage of little or no scale effects provided the structure is approximately the size of interest. However, they show some reservations on the measurement accuracy of field data for independent and dependent variables. They mention that another important parameter that is usually missing in field data is the level of maturity of the scour hole at the time of measurement.

Mueller and Wagner [13] reported 493 field data measurements for observed scour depths at bridge piers in USA. However, only 52 measurements have scour depths greater than or equal to $2.0 \mathrm{~m}$ while measurement accuracy usually is about $0.2 \mathrm{~m}$ and sometimes $0.6 \mathrm{~m}$ as shown in Table 1. Mueller and Wagner [13] in their evaluation of scour published equations used only 266 measurements which met all their criteria such as the following: the flow aligned with the piers, debris not substantial, noncohesive material, and the velocity competent to erode the mean particle size of the bed material. Discussion of this data base is limited due to space availability.

It is assumed here that those scour holes with relatively significant scour depths $\geq 2.0 \mathrm{~m}$ are matured enough and at equilibrium conditions. Maturity or equilibrium condition is a basic assumption in all scour prediction formulae. In Mueller and Wagner [13], measurements numbers 207 and 212 and scour depths of $2.7 \mathrm{~m}$ and $4.0 \mathrm{~m}$ are reported to have zero velocity which shows error in data reporting even in this widely used field data set. These two piers are discarded from being selected in testing the scour prediction equations. Among the remaining 50 measurements with scour depths $\geq 2.0 \mathrm{~m}, 39$ cases are for single piers while the rest are for group piers. Since all of the scour formulae presented here are for single piers, therefore, only the 39 single piers are selected from Mueller and Wagner [13] data set to test the scour equations and are shown in Table 1. Only two cases exist with small skew angles of $11^{\circ}$ and the normal to pier component of the velocity was used in scour calculation. So in summary, data selection was according to maturity of the scour holes criteria and the fact that those data in which the measurement error is in the order of magnitude of the scour depth are to be discarded.

Some statistical properties for the selected field data in this study are shown in Table 2 for the 39 piers reported by Mueller and Wagner [13]. The channel water depth ranges from $2.7 \mathrm{~m}$ to $22.5 \mathrm{~m}$, the approach velocity from $0.7 \mathrm{~m} / \mathrm{s}$ to $3.2 \mathrm{~m} / \mathrm{s}$, the pier width from $1.5 \mathrm{~m}$ to $5.5 \mathrm{~m}, D_{50}$ from $0.18 \mathrm{~mm}$ to $14 \mathrm{~mm}, D_{84}$ from $0.4 \mathrm{~mm}$ to $42 \mathrm{~mm}$, the scour depth from $2.0 \mathrm{~m}$ to $7.7 \mathrm{~m}$, the Froude number from 0.079 to 0.447 , water depth/pier width from 1.27 to 5.38 , and pier width $/ D_{50}$ ratio from 107 to 14333 . When data is needed for $D_{90}, D_{84}$ is used instead. Mueller and Wagner [13] stated that, "unlike laboratory investigations, the distribution of the data cannot be precisely controlled in the field." From Table 2 it is clear that the data tend to group near the average of the minimum and maximum values except for $D_{50}$ and $D_{84}$ while the 266 data points from Mueller and Wagner [13] tend to group near the low end of most of the primary variables.

Figure 4 shows plot of the angle of repose, calculated from (23), versus the mean sediment diameter $D_{50}$ given in $\mathrm{mm}$. According to Figure 4, the angle of repose is at a maximum value of $45.36^{\circ}$ at $D_{50}$ of $0.18 \mathrm{~mm}$ while at a minimum of $34.91^{\circ}$ at $D_{50}$ of $6.9 \mathrm{~mm}$. The angle of repose of wet sand is reported by Clover [42] to be approximately $45^{\circ}$. 
TABLE 1: Scour field data, Mueller and Wagner [13].

\begin{tabular}{|c|c|c|c|c|c|c|c|c|c|}
\hline Measurement & $\begin{array}{c}\text { Shape } \\
\text { Coefficient }\end{array}$ & $\begin{array}{l}\text { Water depth } \\
(\mathrm{m})\end{array}$ & $\begin{array}{c}\text { Velocity } \\
(\mathrm{m} / \mathrm{s})\end{array}$ & $\begin{array}{l}\text { Pier width } \\
(\mathrm{m})\end{array}$ & $\begin{array}{c}\text { Skew } \\
\text { (degree) }\end{array}$ & $\begin{array}{c}D_{50} \\
(\mathrm{~mm})\end{array}$ & $\begin{array}{c}D_{84} \\
(\mathrm{~mm})\end{array}$ & $\begin{array}{c}\text { Scour depth } \\
(\mathrm{m})\end{array}$ & $\begin{array}{c}\text { Accuracy } \\
(\mathrm{m})\end{array}$ \\
\hline 31 & 1 & 3.7 & 2.2 & 1.5 & 0 & 14 & 42 & 2.1 & 0.2 \\
\hline 33 & 1 & 4.3 & 1.7 & 1.5 & 0 & 14 & 42 & 2.4 & 0.2 \\
\hline 40 & 1 & 8.1 & 0.7 & 2 & 0 & 0.18 & 0.4 & 2.7 & 0.2 \\
\hline 164 & 1 & 11.3 & 2.6 & 4.3 & 0 & 0.3 & 0.4 & 2.1 & 0.3 \\
\hline 223 & 1 & 2.7 & 2.3 & 2.4 & 0 & 7.51 & 23.2 & 2 & 0.3 \\
\hline 252 & 1 & 9.2 & 1.6 & 1.7 & 11 & 6.9 & 15 & 2.3 & 0.3 \\
\hline 43 & 0.9 & 9.1 & 1.5 & 3 & 0 & 0.32 & 0.5 & 3.3 & 0.2 \\
\hline 140 & 1 & 22.5 & 2.4 & 4 & 11 & 0.6 & 1.3 & 7.1 & 0.6 \\
\hline 141 & 1 & 22.4 & 2 & 4.1 & 4 & 0.6 & 1.3 & 6.2 & 0.6 \\
\hline 142 & 1 & 16.7 & 1.8 & 4.7 & 4 & 0.6 & 1.3 & 6.5 & 0.6 \\
\hline 153 & 0.8 & 11.6 & 2.6 & 4.3 & 0 & 0.3 & 0.4 & 3.7 & 0.6 \\
\hline 155 & 0.8 & 9.4 & 2.1 & 4.3 & 0 & 0.3 & 0.4 & 3.5 & 0.3 \\
\hline 157 & 0.8 & 11.9 & 3.2 & 4.3 & 0 & 0.3 & 0.4 & 7 & 0.6 \\
\hline 158 & 0.8 & 12.6 & 3.2 & 4.3 & 0 & 0.3 & 0.4 & 5.2 & 0.6 \\
\hline 159 & 0.8 & 9.8 & 2.9 & 4.3 & 0 & 0.3 & 0.4 & 7.7 & 0.3 \\
\hline 160 & 0.8 & 9.8 & 2.9 & 4.3 & 0 & 0.3 & 0.4 & 5.6 & 0.3 \\
\hline 161 & 0.9 & 11.7 & 2.5 & 4.3 & 0 & 0.3 & 0.4 & 4.4 & 0.3 \\
\hline 162 & 0.9 & 11.7 & 2.5 & 4.3 & 0 & 0.3 & 0.4 & 3.9 & 0.6 \\
\hline 163 & 0.9 & 10.8 & 2.6 & 4.3 & 0 & 0.3 & 0.4 & 3.3 & 0.6 \\
\hline 165 & 0.9 & 9.3 & 2.1 & 4.3 & 0 & 0.3 & 0.4 & 4.2 & 0.3 \\
\hline 166 & 0.9 & 9.3 & 2.1 & 4.3 & 0 & 0.3 & 0.4 & 3.8 & 0.3 \\
\hline 167 & 0.9 & 12 & 3 & 4.3 & 0 & 0.3 & 0.4 & 4.5 & 0.3 \\
\hline 168 & 0.9 & 11.7 & 3 & 4.3 & 0 & 0.3 & 0.4 & 4.8 & 0.6 \\
\hline 169 & 0.9 & 11.2 & 3.2 & 4.3 & 0 & 0.3 & 0.4 & 5.5 & 0.3 \\
\hline 170 & 0.9 & 11.7 & 3.2 & 4.3 & 0 & 0.3 & 0.4 & 5.2 & 0.3 \\
\hline 171 & 0.9 & 9.6 & 2.9 & 4.3 & 0 & 0.3 & 0.4 & 5.6 & 0.6 \\
\hline 172 & 0.9 & 9.7 & 2.9 & 4.3 & 0 & 0.3 & 0.4 & 3.7 & 0.3 \\
\hline 196 & 1 & 11.8 & 1.6 & 5.3 & 0 & 0.48 & 0.67 & 4.6 & 0.2 \\
\hline 197 & 1 & 9.5 & 1.4 & 5.4 & 0 & 0.48 & 0.67 & 4.2 & 0.2 \\
\hline 198 & 1 & 8.7 & 1.1 & 5.5 & 0 & 0.48 & 0.67 & 3.1 & 0.1 \\
\hline 208 & 1 & 14.3 & 1.9 & 2.8 & 0 & 0.7 & 2.1 & 4.3 & 0.6 \\
\hline 209 & 1 & 15.1 & 2 & 2.8 & 0 & 0.7 & 2.1 & 3.8 & 0.6 \\
\hline 210 & 1 & 12.9 & 1.2 & 2.8 & 0 & 0.7 & 2.1 & 3.8 & 0.6 \\
\hline 211 & 1 & 11 & 1.1 & 2.8 & 0 & 0.7 & 2.1 & 4.3 & 0.6 \\
\hline 213 & 1 & 14.6 & 2.3 & 2.9 & 0 & 0.7 & 2.1 & 4 & 0.6 \\
\hline 214 & 1 & 15.4 & 2 & 2.9 & 0 & 0.7 & 2.1 & 3.7 & 0.6 \\
\hline 215 & 1 & 12.9 & 1.4 & 2.9 & 0 & 0.7 & 2.1 & 3.7 & 0.6 \\
\hline 216 & 1 & 11 & 1.2 & 2.9 & 0 & 0.7 & 2.1 & 3.7 & 0.6 \\
\hline 217 & 0.8 & 20 & 2.6 & 5.5 & 0 & 0.96 & 2.5 & 4.1 & 0.6 \\
\hline
\end{tabular}

TABLE 2: Summary of scour field data, Mueller and Wagner [13].

\begin{tabular}{|c|c|c|c|c|c|c|c|c|c|}
\hline Property & $\begin{array}{c}\text { Water depth, } \\
H(\mathrm{~m})\end{array}$ & Velocity $(\mathrm{m} / \mathrm{s})$ & Pier width, $b(\mathrm{~m})$ & Scour depth (m) & $D_{50}(\mathrm{~mm})$ & $D_{84}(\mathrm{~mm})$ & $\begin{array}{l}\text { Froude } \\
\text { number }\end{array}$ & $H / b$ & $b / D_{50}$ \\
\hline Minimum & 2.7 & 0.7 & 1.5 & 2.0 & 0.18 & 0.40 & 0.079 & 1.27 & 107 \\
\hline Maximum & 22.5 & 3.2 & 5.5 & 7.7 & 14.0 & 42.0 & 0.447 & 5.38 & 14333 \\
\hline Average & 11.56 & 2.19 & 3.76 & 4.25 & 1.49 & 3.99 & 0.22 & 2.81 & 9555 \\
\hline
\end{tabular}




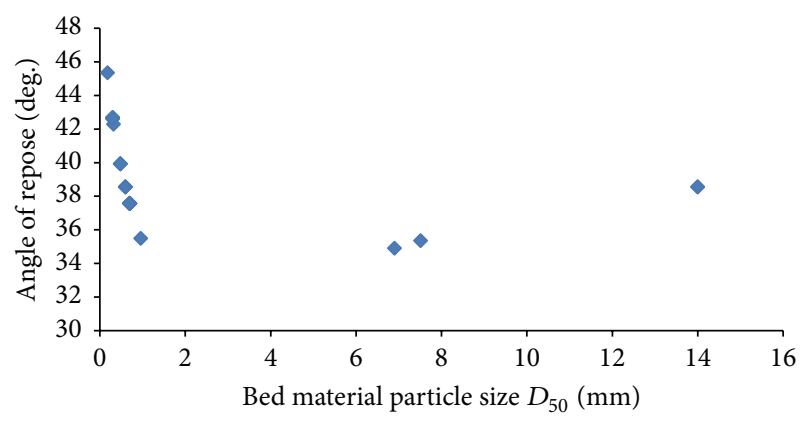

Figure 4: Angle of repose versus bed material particle size $D_{50}$.

\section{Performance Measures of Computed Scour Depths}

Several performance measures are used in this study as follows. The percentage relative error is one measure of the performance of the scour prediction equations. The percentage relative error for a single prediction is defined as

$$
\mathrm{RE} \%=\frac{\left(D_{s}^{\text {Computed }}-D_{s}^{\text {Measured }}\right)}{D_{s}^{\text {Measured }}} \times 100 .
$$

The percentage average absolute relative error of prediction of all data is defined as

$$
\operatorname{AARE} \%=\frac{1}{n} \sum_{1}^{n} \frac{\left|\left(D_{s}^{\text {Computed }}-D_{s}^{\text {Measured }}\right)\right|}{D_{s}^{\text {Measured }}} \times 100,
$$

where $n$ is the number of data points ( $n=39$ here).

Following Sheppard et al. [21], two useful error measuring quantities are used as follows:

$$
\mathrm{SSE} \%=\frac{\sum\left(D_{s}^{\text {measured }}-D_{s}^{\text {computed }}\right)^{2}}{\sum\left(D_{s}^{\text {measured }}\right)^{2}} \times 100,
$$

where SSE\% is sum of the squares of the error. The second one for the normalized scour depths $D_{s} / b$ is

$$
\operatorname{SSEn} \%=\frac{\sum\left(D_{s}^{\text {measured }} / b-D_{s}^{\text {computed }} / b\right)^{2}}{\sum\left(D_{s}^{\text {measured }} / b\right)^{2}} \times 100
$$

where SSEn\% is sum of the squares of the normalized error.

\section{Application of Bridge Pier Scour Equations}

Table 3 shows the relative errors according to (24) resulting from application of the equations cited herein to the field data in Table 1. It should be noted that for circular piers the calculated scour depth, which was calculated based on rectangular pier assumption, is multiplied by a correction factor of 0.9 . For sharp nosed piers, a correction factor of 0.8 is used. Table 1 shows the shape correction factors for each case.

It is clear from Table 3 that the equations of Neill [14], Shen et al. [15], CSU [16], Breusers et al. [17], Jain and
Fischer [18], Froehlich [19] with safety factor, and Melville [20] are significantly overpredicting the scour depth as can be seen from the high relative error values. This shows that these equations are really design equations which are very conservative and underpredictions of scour depths are rare. Contrary to that is the equation by Froehlich [19] without the safety factor which greatly underpredicts the scour depth in almost all cases. The equations of $\mathrm{Hafez}$ [10], Sheppard/Melville [21], and the present study have reasonable relative errors with most overpredictions and few underpredictions. In other words, these equations tend to predict or estimate field scour depths. The factor $\eta$ was assumed as 0.75 and 1.0 when applying Hafez [10] and present study equation (21), respectively. The reason is that $\mathrm{Hafez}$ [10] is basically based on two-dimensional analysis where variation of the velocity and scour hole depth is assumed to be constant across the width of the channel. To compensate for three-dimensional effects, velocity is multiplied by 0.75 in the equation of Hafez [10]. Since the present approach considers the three-dimensional aspects of the scour hole, $\eta$ is assumed unity reflecting conversion of all horizontal momentum into vertical downward momentum. Because no data are reported for the channel width or bridge span, effect of the contraction scour due to channel constriction was not considered.

Table 4 shows the average absolute relative error as percentage, AARE\% according to (25), calculated for the 39 data points. This is an average total error which includes over- and underpredictions. Underpredictions are shown in the next row in Table 4. Among all equations, the present study developed equation has the minimum value of AARE\% as $26.1 \%$ followed by Hafez [10] with a value of $32.5 \%$ and then Froehlich [19] with no safety with a value of $32.7 \%$ and fourthly by Sheppard/Melville [21] with a value of $34.8 \%$. However, among the $32.6 \%$ by Froehlich [19] with no safety, the underpredictions contribute $30.6 \%$ which discounts this method and it will not be considered in further analysis. The remaining equations have relatively high AARE\% ranging from $40.4 \%$ for CSU [16] equation up to $107.8 \%$ for Melville [20]. This confirms the finding that Melville [20] equation is derived as an envelope to scour data which classifies this method as a very conservative design equation and not as a prediction equation. Clearly, all the equations with high total error have very small underpredictions or negative errors. The present study has $4.6 \%$ underpredictions of AARE\% which results in $21.5 \%$ for overprediction. Based upon AARE\% criteria, the present study comes first, followed by Hafez [10], and then comes Sheppard/Melville [21]. The under AARE\% for these three methods is fairly small ranging from $2.9 \%$ to $4.6 \%$.

Table 4 shows the sum of squares of the error for each equation as total and under errors. For the total error, the present study provides the least total SSE\% with $8.7 \%$ followed by Sheppard/Melville [21] with $11.4 \%$ and then by Hafez [10] with $12.3 \%$ and the CSU [16] with $17.5 \%$. The remaining equations have relatively high SSE\% but as expected have very low SSE\% underprediction error which emphasizes their nature as conservative design equations. For the under SSE\%, the three equations of Hafez [10], the present 


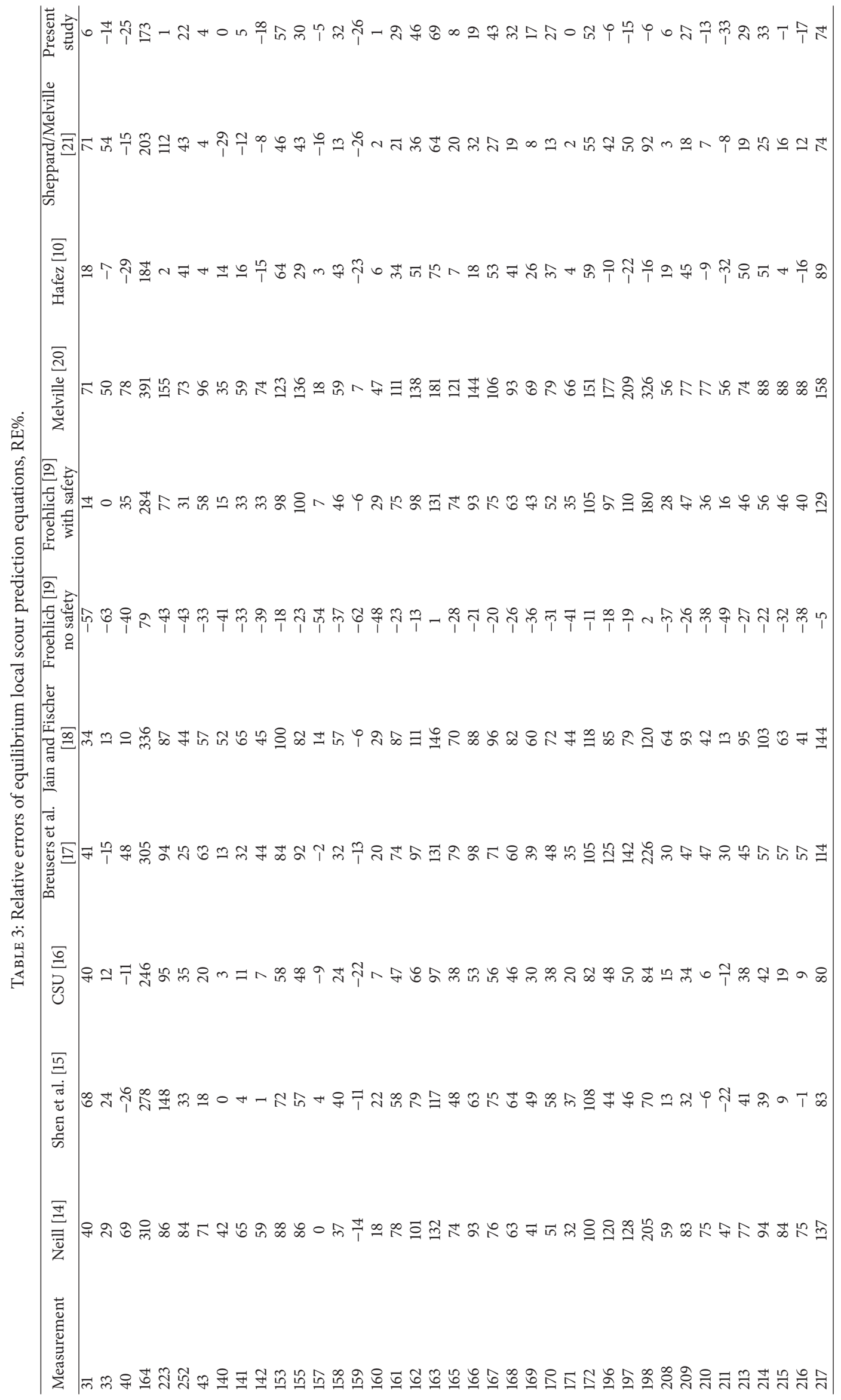




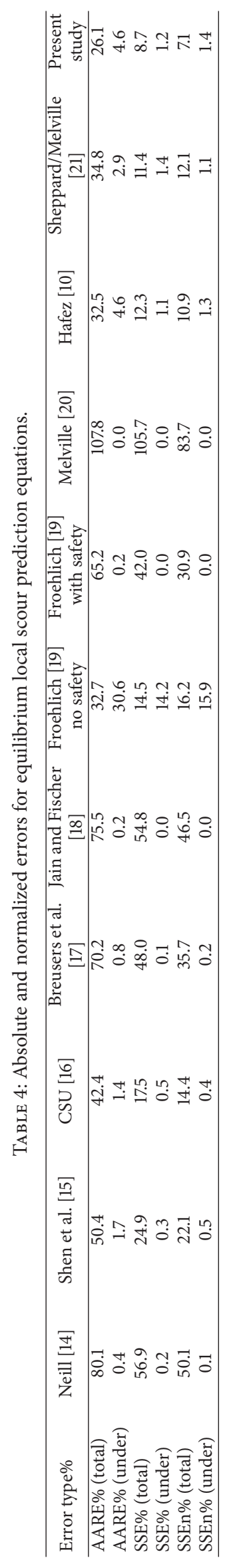


study, and Sheppard/Melville [21] have small but nearly equal errors of 1.1, 1.2, and 1.4, respectively.

For the sum of the squares of the normalized error in Table 4, again the present study and then Hafez [10] followed by Sheppard/Melville [21] come in the first three places with total SSEn \% of 7.1\%, $10.9 \%$, and $12.1 \%$, respectively. For these three equations their SSEn\% (under) has relatively higher values compared to the rest of the equations with values ranging from $1.1 \%$ to $1.4 \%$. CSU [16] comes close with SSEn\% (total) of $14.4 \%$ while the remaining equations have higher values.

It should be noted as can be seen from Table 3 that all of the equations herein, except Froehlich [19] equation with no safety, highly overpredict the scour depths at seven measurements, namely, 164, 153, 162, 163, 167, 172, and 217. This might be due to the fact that the scour holes have not reached equilibrium yet, that is, have not matured enough, or that some uncertainties exist in the measured values of the variables needed to calculate the scour depths or that filling of the scour holes have taken place in the receding part of the flood hydrograph. The calculated critical velocity is always higher than the average velocity for all the 39 cases, except at measurement 252, which indicates live bed scour conditions dominate for almost all cases.

Live bed conditions indicate that contraction and general scour might have been taking place. The equations cited herein predict basically local scour. Lu et al. [23] in their study of flood events induced by Typhoons Mindulle (2004) and Dujuan (2003) at the Si-Lo Bridge in central Taiwan found that more than $79 \%$ of the total scour depth is attributed to local scour and that general scour plays an important role in high flows. They report that due to the relatively wide spans between the bridge piers where the pier width is $3.5 \mathrm{~m}$ and the bridge span is $62.5 \mathrm{~m}$, only $5 \%$ of the total scour depth is attributed to contraction scour at peak flows. If it is assumed here that the local scour is $79 \%$ of the total scour then all the calculated scour depth values in this study might be multiplied by a factor of $1.27(=1 / 0.79)$ to yield new total scour depths which should be compared to the measured scour depths in Table 1. Therefore, if the predictions of the present study are multiplied by this factor all the prediction values will be greater than the measured ones except at one case only, namely, at measurement 211, where the underprediction amounted to $33 \%$. However, even other equations which usually overpredict the scour depth underpredicted this scour depth by $22 \%$, for example, in Shen et al. [15] equation. The accuracy in measuring the scour depth is $0.6 \mathrm{~m}$ at measurement 211; that is, the measurement error alone amounts to $14 \%$ (Mueller and Wagner [13] did not specify if the measurement error is positive or negative). For use of (21) in bridge design, it is recommended that a factor of safety of about 1.3 is used for bridges having life time up to 50 years while using a factor of safety of 1.5 for bridges having life time more than 50 years.

Other factors can also contribute to underpredictions of the scour depths by the present study. Among these factors is that the velocity, $V_{x}$, needed in (21) should be that velocity just upstream of the bridge pier but most data sets provide the approach cross-sectional average velocity, $V$. Indeed $V_{x}>V$ due to contraction of the flow caused by reduction of the flow area resulting from the bridge pier constriction effect. For lack of data, especially field data, about scour hole upstream slope and scour hole-width, the angle of repose is used to compensate for this. Also, accurate data for the porosity of the bed material are usually not reported and the porosity is assumed herein as 0.4. Despite the many factors contributing to the uncertainty in the input data used to predict scour hole depths at bridge piers, the present study developed equation comes first when it is applied to the field data set in Table 1 followed by Hafez [10] and then Sheppard/Melville [21].

\section{Discussions}

Equation (21) does not suffer from the wide pier problem even if the pier width tends to an infinite value as in such case it is reduced to (22) in which the pier width does not appear explicitly. Examples of cases of very wide piers are caissons, coffer dams, and river, and marine islands where scour occurs often upstream. Unfortunately, field scour data rarely exist to aid in validation of scour at wide piers. Also for floods attacking cities and urban areas, wide houses are surrounded by water from all directions and can be treated as wide obstructions or bridge piers. Their collapse by floods can be due to the scouring action of the flood water which can undermine their shallow foundations.

The factor $\eta$ is a unique coefficient because it can be derived from theoretical considerations and physical reasoning. Its ideal value is unity $(\eta=1)$ which indicates that all the attacking flow momentum or energy is transferred to downflow momentum or energy responsible for forming the scour hole. Often it is difficult to know the actual hydrodynamic flow parameters (velocity, depth, etc.) under field conditions that actually cause certain scour hole (i.e., the scour forming velocity, depth, or discharge). In this case other values than unity might be assumed for $\eta$. If there are reliable field data where the hydrodynamic flow variables are really the actual ones that cause the measured scour depth or geometry, then estimation of $\eta$ can be performed and this is an open area for further research. However such reliable and accurate field data are rare to find. Most scour holes occur at severe flooding conditions for which accurate measurements or recordings are difficult. Computational fluid dynamic models can help in this regard.

There are, however, cases that definitely indicate incomplete transfer of energy or approach horizontal momentum into vertical downward momentum, for example, due to flow inclination, roughness of bridge piers, shape of the piers, piers with scour countermeasures such as piers with collars or side bars, piers with holes or slots, piers with piles in front of them, and similar factors. No calibration and verification procedure for $\eta$ was actually implemented herein. But when applying Hafez [10] equation, $\eta$ was assumed to be less than unity and equal to 0.75 , based on the laboratory observations in which the magnitude of the vertical downward velocity $V_{z}=0.5$ to 0.8 of the approach flow velocity $V_{x}$. Graf and Istiarto [43] report $V_{z}=-0.6 \mathrm{~V}$, and Raudkivi [8] reports for circular piers that the maximum velocity of the downflow occurs at 0.05 to 0.02 pier diameters upstream of it, reaches 0.8 times the mean 
approach velocity, and occurs in the scour hole at about one pier diameter below the bed level. For rectangular piers, it is expected that the downward velocity may be equal to the mean approach velocity.

Sometimes lateral flow momentum (e.g., flood plain flow or side channels) can transfer energy to the longitudinal flow momentum; thus $\eta$ can be even greater than unity. In principle, therefore, $\eta$ can vary from case to another depending on the hydraulic, pier, and field conditions. For fully developed scour holes where all the energy in the attacking fluid is converted to an energy in removing the bed material out of the scour hole $\eta=1$, for underdeveloped scour holes, $\eta$ is less unity. For overdeveloped scour holes where lateral flows add momentum to the longitudinal momentum $\eta$ can be greater than unity. As such, $\eta$ accounts for different conditions existing in the field. It can be assumed that $\eta=$ the work done in removing the bed material out of the scour hole/the work done by the attacking jet flow.

The combination $\left(\eta V_{x}=V_{z}\right)$ may be interpreted as reflecting the downflow component of the velocity caused by the pier obstruction where $V_{z}$ is the vertical downflow velocity in front of the pier. Indeed, the downflow is responsible for the upstream scour and may be determined from vertical 2D or 3D numerical hydrodynamic models or experimental measurements. For the sake of simplicity herein, the factor $\eta$ has been assumed based on theoretical considerations and physical reasoning. It could be postulated that (21) is also valid for predicting scour depths downstream bridge piers when a proper selection of the momentum transfer coefficient $\eta$ is made. In this case, $\eta$ represents the transformation of momentum from either the horseshoe or wake turbulent eddies to the bed material particles and this can be an added advantage of the present approach.

It should be noticed that this approach is some sort of a global incipient motion concept but based on energies rather than on forces. In classical incipient motion, balance of forces is applied to a typical sediment bed-particle. In the energy balance theory, balance of energy (or work) is used instead of balance of forces. The whole material in the scour hole is considered as a one big particle (mega sediment particle). When the flow jet exerts work that is equal to the work needed to move this mega sediment particle out of the scour hole, the equilibrium geometry of the scour hole is attained.

In other words, given certain flow hydrodynamic conditions (velocity, depth), pier geometry, and certain sediment properties (sediment specific gravity, porosity, size, and angle of repose), some conditions produce certain energy or work which can erode the bed material (assuming unlimited bed material along its depth and no paving of the bed occurs) to an extent that the exerted work is exactly the work needed to lift or carry the sediment particles out of the scour hole. From the laws of mechanics, the work done by a group of forces is equal to the work done by the resultant of these forces. This last statement is utilized to deal with the scour hole as one mega particle having weight force acting at the center of mass of the scour hole.

The ease by which scour at other structures than bridge piers can be modeled mathematically using the energy balance theory supports the generality or universality of this approach. Scour due to horizontal jets from sluice gate opening, scour at abutments, groins, dykes, and plunge pools are among these examples that novel scour equations can be developed based on the same principles of the energy balance theory.

It can be inferred from the present study theoretically based equation (21) that $D_{s} \approx F_{r}^{2 / 3}$. Shen's et al. [15] equation, (2) which is based on flume data at Colorado State University laboratory has the dimensionless scour depth also proportional to $F_{r}^{2 / 3}$. In addition the Modified Froehlich formula by Fischenich and Landers [11] based upon observed field scour depths in sand and gravel-bed streams is given as

$$
\frac{D_{s}}{H}=2\left(\frac{\theta}{90}\right)^{0.13}\left(\frac{b}{H}\right)^{0.43} F_{r}^{0.61}+1,
$$

where $\theta$ is the angle of embankment to flow (degrees). In (28) the dimensionless scour depth is proportional to $F_{r}^{0.61}$ that is an exponent value of 0.61 which is very close to the $2 / 3(\approx 0.67)$ value derived from pure theoretical considerations in the present approach. Therefore, the Froude number variation with the scour depth derived from both laboratory and field data is nearly equal to the variation in the present theoretical study.

Regarding live bed scour which is significant in the rising period of high floods, this can be considered in two ways.

(a) The momentum transfer coefficient, $\eta$, can be adjusted to account for effects of the sediment transport and the change in turbulence intensities which affect the velocity structure. Parallel to or separate from that is the use of $\left(V_{x}^{2}-V_{c}^{2}\right)$ instead of $V_{x}^{2}$ in (21) which shows the flexibility of the present method through including critical conditions for incipient motion of the bed sediments.

(b) The effect of bed load can be taken in a more direct manner by considering the loss of work due to exerting extra work in moving the bed load. The work done in moving the bed load inside the scour hole can be assumed as

$$
W_{\mathrm{bl}}=\rho_{b} q_{b} b U_{b}\left(\frac{D_{s}}{\sin \varphi}\right),
$$

where $W_{\mathrm{bl}}$ is the work exerted by the flow in moving the bed load across the scour hole length, $\rho_{b}$ is the density of the bed load material, $q_{b}$ is the bed load per unit width, and $U_{b}$ is the velocity of bed load particles. This work can be subtracted from the work done by the fluid flow, which was given in (15), as

$$
W_{\text {net }}=\rho V_{x}^{2} H b \eta^{2}\left(0.7 H+\frac{D_{s}}{2}\right)-W_{\mathrm{bl}},
$$

where $W_{\text {net }}$ is the net available work or flow energy of the attacking flow after accounting for the work consumed in moving the bed load. This will result in less work available for removing the bed material out of the scour hole and the scour depth should decrease in this case due to the bed load. A similar treatment can be done for the suspended load if it is significant. The volume of the scour hole, Vol. in (16), can also be adjusted to account for the live bed conditions as the new Vol. $=$ Vol. in (16) $\pm q_{b} b t_{s}$, where $t_{s}$ is the time 
to reach the equilibrium scour hole and + or - depends on having either scouring or filling conditions of the scour hole. The time taken for equilibrium scour depth to develop can be given from the formula of Melville and Chiew [44]. During the recession part of the flood, the velocity is greatly reduced and consequently the energy is reduced enough to deposit the bed load in the scour hole.

Effects of pier shape and other variables such as the level of turbulence could be reflected in the momentum transfer factor $\eta$. However, these factors were extensively studied and correction factors were produced like in HEC-18 manual. It might be sufficient to just use these correction factors as multiplying factors to original scour equation (21) which deals with the ideal case of rectangular piers, orthogonal flow, and nonuniform bed material.

Though the role of the horseshow vortices is observed experimentally and recognized by past researchers, this effect neither is reflected in existing scour equations nor can be explained by these equations. Herein is a trial to shed some light on the way these vortices originate and the role they might play in pier scour. From turbulence theory, Schlichting [45], the flow instantaneous velocity, $V_{\text {inst }}$, is related to the time average velocity, $V_{x}$, through $V_{\text {inst }}=V_{x}+v$, where $v$ is the longitudinal velocity turbulent fluctuation. Accordingly, the square of the instantaneous velocity can be written as

$$
V_{\text {inst }}^{2}=\left(V_{x}+v\right)^{2}=V_{x}^{2}+2 V_{x} v+v^{2}
$$

Applying time averaging (the time scale of the averaging process is small compared to the time scale of the scour phenomenon) to both sides of (31) yields

$$
V_{\text {inst }}^{2}=V_{x}^{2}+v^{2}
$$

where the variables appearing in (32) are now time averagedquantities. Now, this flow jet instantaneous velocity is used in (15) instead of the time average velocity to yield

$$
\begin{aligned}
W_{\text {in }}= & \frac{\rho V_{x}^{2} H b \eta^{2}}{(1-b / B)^{2}}\left(0.7 H+\frac{D_{s}}{2}\right) \\
& +\rho v^{2} H b \eta^{2}\left(0.7 H+\frac{D_{s}}{2}\right) .
\end{aligned}
$$

The second term on the right hand side of (33) represents additional work or energy which is a sort of turbulence energy and it is this energy that is thought to be the source mechanism for the horseshoe vortex system. The quantity $v^{2}$ is directly related to the turbulent normal stress. Graf and Istiarto [43] in their experimental investigation report that the longitudinal turbulence intensities are the dominant one among the other components of the turbulence intensities over the entire flow depth and the square root of $v^{2}$ can reach up to $9 u_{*}$, where $u_{*}$ is the shear velocity. This additional turbulence or vortex energy is available for transporting the eroded material out of the scour hole as stated early by Raudkivi [8].

The developed equation from the present study can be easily modified to include the effects of some scour mitigation measures. The goal of scour mitigation or protection works is to reduce the velocity or energy of the attacking flow jet upstream of the pier. For example, perforated piers (piers with longitudinal holes or slots) are used to reduce the downflow component and reduce the block discharge. The new block discharge at the pier can be modified as $Q_{b 1}=V_{x} H b-$ $V_{x} A_{h}$ where $Q_{b 1}$ is the new block discharge and $A_{h}$ is the total area of holes. The new block discharge can then be incorporated easily into the derivation of the present study equation shown before. Reduction of the block discharge will definitely reduce the scour depth. In a similar fashion but with opposite effect, debris can be taken into account by estimating the amount of increase in flow blockage due to debris and modify accordingly the increase in the block discharge.

If a single pile or group of piles are positioned upstream of the main pier, reduction of scour will occur due to reduction of the block discharge (or attacking velocity or force or energy). As in the last case, the new block discharge at the pier can be modified as $Q_{b 1}=V_{x} H b-V_{x} A_{p}$, where $Q_{b 1}$ is the new block discharge, $A_{p}$ is the total projected area of the piles, $A_{p}=\sum H b_{p}, b_{p}$ is the width or diameter of the pile, and $\sum$ indicates summation over the number of piles in case of pile group. Now the present approach provides a way of designing scour protection methods. If the scour depth is required to have a certain value, this value could be substituted into (21) after it is written in terms of the block discharge which can be determined in this case. After determination of the block discharge, then the dimensions of the protective piles or pier slot area can be calculated.

If horizontal collars or side bars around the pier are fastened to reduce the downflow velocity component, consequently reducing the scour depth, its effect can be incorporated through the coefficient $\eta$ which will then have a value less than 1.0. Chen et al. [46] investigated experimentally the flow field around a bridge pier with hooked collar with a diameter of $1.25 b$ ( $b$ is the pier diameter). They found that installing the hooked collar at the bed level reduces the downflow in the immediate vicinity of the pier. The experiment without the hooked collar had the maximal downflow, whereas the experiments with the hooked collar had approximately $25 \%$ of the maximal downflow and the maximum turbulent kinetic energy decreased by approximately $60 \%$ compared with the case when using no collar. Their measured (by acoustic Doppler Velocimeter) vertical velocity just in front of the pier was reduced from $-7.0 \mathrm{~cm} / \mathrm{s}$ in case of no collar to $-1.75 \mathrm{~cm} / \mathrm{s}$ in case of collar located on the bed level. Velocity with a collar is then $25 \%$ of that without collar. This is because the hooked collar dissipates the energy of the downflow above the collar by $60 \%$. Note that the reduction of velocity is $0.75^{2}=0.56$ which is almost equal to the reduction of the turbulent kinetic energy $(\approx 0.6)$. This confirms the theoretical finding before the fact that the turbulent kinetic energy is proportional to the square of the velocity. If the reduction of velocity is $75 \%$ and according to (21) the scour depth is proportional to $2 / 3$ power of velocity, then reduction of the scour depth will reach $82 \%$. Chen et al. reported no sign of scouring and horseshoe vortex at the upstream face of the pier. Observe the connection between the turbulent kinetic energy $\left(\approx v^{2}\right)$ and the horseshoe vortices 
as mentioned in the discussion after (33). By establishing a relation between the hooked collar diameter and also the location with respect to the bed level with the reduction coefficient of velocity maximum then this relation can be used for the determination of $\eta$.

Another added advantage of (21) is that the bed material characteristics appear through inclusion of the bed material specific gravity, porosity, and angle of repose which is not present in most existing pier scour equations. Sediment size effects are implicitly included through the angle of repose as seen from (23). Most, if not all, existing bridge pier scour equations assume that the bed sediment is cohesionless sediments which are typical sands with specific gravity $=$ 2.65. There might be other situations where due to river bed mining the river bed material can be different from sands and have varying specific gravities. Ghorbani [22] used a vacuum air removal technique to measure the specific gravity in rivers in Iran and reported measured values of specific gravity other than 2.65 such as $2.5,2.62$, and 2.67. Yu et al. [47] in their experimental investigation of scour formation used bed material as lightweight cylindrical plastics with a specific gravity of 1.05 . They used four existing scour prediction methods (the modified 65-1R Chinese equation, Gao's [48] equation, Melville [20] method, and the modified HEC-18 formula) and found that none of the methods are applicable for lightweight bed material. They attributed the main reason to the fact that the effect of density of bed material is not sufficiently considered in these formulae. They noted that almost all the scour formulae are based on natural quartz sediments and it is doubtful if these formulae are still valid in the case of nonquartz or lightweight material. This is a valid consideration, by them, as one generally uses lightweight material in a physical model, so as to satisfy the various modeling requirements. The present study developed equation has the specific gravity of the bed material as an explicit variable and can be used for nonsands as well, which is a unique feature. In addition, porosity of the bed material appears in (21) and for cohesive beds porosity can be assumed to be zero (i.e., $\theta=0$ ). In that case, the present study equation can be used for near cohesive bed sediments while using appropriate value for the upstream slope of the scour hole $(\phi$ in this case).

Present study equation (21) can be applied to any fluid type (such as mudflows, debris flows, and air flows) and any bed material type (such as clays, nonquartz materials, and snow). This is done by considering the appropriate fluid density in (15) and the appropriate bed material specific weight in (17). Existing equations are only developed for water as the fluid and sands as the bed material which limit their use.

The present study developed equation is purely theoretical; however it adds to the understanding of the physics of the scour mechanism and it performs very well when applied to some USA field data. It is based on the conservation of energy which is a sound theoretical concept. The developed equation explains (1) the role of each variable involved in the scour phenomenon, (2) the effects of bed material sediments characteristics such as the specific gravity (density), porosity, size, and angle of repose, clear water and live bed scour, slender and wide piers, and debris effects, and (3) the effects of scour mitigation methods such as collars or slots. Both laboratory data, due to its scale effects, and field data, due to uncertainty in field measurements and maturity of scour holes, have weaknesses in testing of pier scour equations. Therefore little trust can be put on these data unless selected very carefully which is a very challenging task. Trust can be established on widely accepted scientific concepts such as the conservation of energy concept whose reliability has been proven in physics, mechanics, and many sciences. As the present study approach is built on this sound and valid concept of energy conservation, its reliability can be assumed subject to the validity of the assumptions made herein. The developed equation can be even used to judge the quality of field data by comparing the calculated attacking flow energy versus the energy required to move the measured volume of the scoured material, that is, checking the work or potential energy balance. It should be noted that the present approach deals with pier scour due to hydrodynamic forces attacking bridge piers and bed sediment properties. To account for other important factors such as pier shape, pier alignment, and channel geometry effects on pier scour, multiplying coefficients can be used, for example, from (10). For the time development of the scour hole or for group piers which are outside the scope of the current work, other equations found in the literature might be used.

\section{Conclusions}

A purely theoretically derived bridge pier scour equation has been shown to perform very well when compared to selected field pier scour data of Mueller and Wagner [13]. The data selected are the ones in which the scour holes had achieved maturity and the measurement error is not of the same order of magnitude as the measured scour depth. The equation is based on the sound concept of energy conservation through energy balance theory where balance exists between the attacking flow potential energy upstream of the bridge pier and the potential energy needed to scour the bed material out of the scour hole upstream of the pier. The developed equation has several advantages among which is that it adds to the understanding of the physics of bridge pier scour, is valid for slender (normal) and wide piers, is valid for cohesionless and cohesive sediments, and does not suffer from overpredictions of scour depths. In addition, it addresses clear water and live bed scour, includes effects of the bed material specific gravity (or density), porosity, size, and angle of repose, and debris effects, and can handle scour mitigation methods such as collars, side bars, slots, and pier protection piles. The present approach provides means to design such scour mitigation methods. The present study equation is compared to commonly used bridge scour equations. These equations are the those of Neill [14], Shen et al. [15], CSU [16], Breusers et al. [17], Jain and Fischer [18], Froehlich [19] with and without safety, Melville [20], Hafez [10], and Sheppard/Melville [21]. When applied to 39 scour field pieces of data in USA reported in the Mueller and Wagner [13], the present study equation came first followed by Hafez [10] then by Sheppard/Melville [21]. The present 
TABLE 5

\begin{tabular}{lc}
\hline Velocity power law exponent $(m)$ & $y_{\text {C.G. }}$ \\
\hline 6 & $0.700 H$ \\
7 & $0.695 H$ \\
8 & $0.692 \mathrm{H}$ \\
9 & $0.690 \mathrm{H}$ \\
10 & $0.687 \mathrm{H}$ \\
\hline
\end{tabular}

study equation yielded the least average absolute error, least total error, and least underprediction error when predicting scour depths. Further testing of the developed equation using more accurate field data is highly recommended. For use of the developed equation in bridge design, to account for any uncertainties, it is recommended that a factor of safety of about 1.3 is used for bridges having life time up to 50 years while using a factor of safety of 1.5 for bridges having life time more than 50 years.

\section{Appendix}

The blocked flow force on the average was given earlier as shown in (14). The local longitudinal velocity at a height, $y$, above the bed level is proportional to $y^{(1 / m)}$ according to the well-known power law of velocity distribution in open channels.

Equation (14) can be written in proportionality fashion as a function of the vertical coordinate, $y$, measured from the river bed as

$$
F_{b} \approx y^{2 / m} y \approx y^{(2+m) / m} .
$$

The distance of the point of influence of this force, $y_{\text {C.G. }}$, measured above the river bed can be calculated from the following equation:

$$
y_{\text {C.G. }}=\frac{\int_{0}^{H} y y^{(2+m) / m} d y}{\int_{0}^{H} y^{(2+m) / m} d y} .
$$

Integration of (A.2) yields

$$
y_{\text {C.G. }}=\frac{2+2 m}{2+3 m} H .
$$

Table 5 shows the various values of $y_{\text {C.G. }}$ as a function of the velocity power law exponent $(m)$.

Based on Table 5, a value of $0.7 \mathrm{H}$ can be taken for $y_{\text {C.G. }}$. which corresponds to an exponent $m=1 / 6$ in the velocity power law.

\section{Competing Interests}

The author declares that he has no competing interests.

\section{Acknowledgments}

The author would like to express his deepest appreciation to all of Melivlle B. W., Julien P. Y., Hager W. H., van
Rijn L. C., and Hoffmans G. for their fruitful discussions, suggestions, and feedback about the early work of Hafez [10]. This motivated the development of a more rigorous and general approach which is presented herein. Special thanks go also to Eng. Mohammad Akram Pervez from Yanbu Technical Institute for his help in preparing some figures.

\section{References}

[1] D. Imhof, Risk assessment of existing bridge structures [Ph.D. thesis], University of Cambridge, Cambridge, UK, 2004.

[2] FHWA, Evaluating Scour at Bridges, NH1-01-001, Federal Highway Administration, Washington, DC, USA, 4th edition, 1988.

[3] A. C. Parola, D. J. Hagerty, D. S. Mueller, B. W. Melville, G. Parker, and J. S. Usher, "Need for research on scour at bridge crossings," in Proceedings of the 27th Congress of the International Association of Hydraulic Research (IAHR '97), pp. 124-129, August 1997.

[4] A. M. Shirole and R. C. Holt, "Planning for a comprehensive bridge safety assurance program," Transportation Research Record 1290, Transportation Research Board, Washington, DC, USA, 1991.

[5] K. Wardhana and F. C. Hadipriono, "Analysis of recent bridge failures in the United States," Journal of Performance of Constructed Facilities, vol. 17, no. 3, pp. 144-150, 2003.

[6] L. Brandimarte, P. Paron, and G. Di Baldassarre, "Bridge pier scour: a review of processes, measurements and estimates," Environmental Engineering and Management Journal, vol. 11, no. 5, pp. 975-989, 2012.

[7] W. H. Graf, Fluvial Hydraulics, John Wiley \& Sons, Chichester, UK, 1998.

[8] A. J. Raudkivi, "Scour at bridge piers," in Scouring, H. Breusers and A. J. Raudkivi, Eds., International Association of Hydraulic Research, Balkema, Rotterdam, The Netherlands, 1991.

[9] B. W. Melville and S. E. Coleman, Bridge Scour, Water Resource, LLC, Highlands Ranch, Colo, USA, 2000.

[10] Y. I. Hafez, "A new analytical bridge Pier Scour equation," in Proceedings of the Eighth International Water Technology Conference (IWTC '04), Alexandria, Egypt, 2004.

[11] C. Fischenich and M. Landers, Computing Scour, EMRRP Technical Notes Collection (ERDC TN-EMRRP-SR-05), U.S. Army Engineer Research and Development Center, Vicksburg, Miss, USA, 2000.

[12] T. A. Mohamed, M. J. Noor, A. H. Ghazali, and B. B. Huat, "Validation of some bridge pier scour formulae using field and laboratory data," American Journal of Environmental Sciences, vol. 1, no. 2, pp. 119-125, 2005.

[13] D. S. Mueller and C. R. Wagner, Field Observations and Evaluations of Streambed Scour at Bridges, Office of Engineering Research and Development, Federal Highway Administration, Mclean, Va, USA, 2005.

[14] C. R. Neill, "River bed Scour, a review for bridge engineers," Contract No. 281, Alberta Research Council, Calgary, Canada, 1964.

[15] H. W. Shen, V. R. Schneider, and S. S. Karaki, "Local scour around bridge piers," Journal of the Hydraulics Division, vol. 95, no. 6, pp. 1919-1940, 1969.

[16] Colorado State University, Highways in the River Environment: Hydraulic and Environmental Design Considerations, The Federal Highway Administration, U.S. Department of Transportation, Washington, Wash, USA, May 1975. 
[17] H. N. C. Breusers, G. Nicollet, and H. W. Shen, "Local scour around cylindrical piers," Journal of Hydraulic Research, vol. 15, no. 3, pp. 211-252, 1977.

[18] S. C. Jain and E. E. Fischer, "Scour around circular bridge piers at high Froude numbers," FHwa-RD-79-104, Federal Highway Administration, U.S. Department of Transportation, Washington, DC, USA, 1979.

[19] D. C. Froehlich, "Analysis of onsite measurements of scour at piers," in Proceedings of the National Conference on Hydraulic Engineering, pp. 534-539, ASCE, August 1988.

[20] B. W. Melville, "Pier and abutment scour: integrated approach," Journal of Hydraulic Engineering, vol. 123, no. 2, pp. 125-136, 1997.

[21] D. M. Sheppard, B. Melville, and H. Demir, "Evaluation of existing equations for local scour at bridge piers," Journal of Hydraulic Engineering, vol. 140, no. 1, pp. 14-23, 2014.

[22] B. Ghorbani, "A field study of scour at bridge piers in flood plain rivers," Turkish Journal of Engineering and Environmental Sciences, vol. 32, no. 4, pp. 189-199, 2008.

[23] J.-Y. Lu, J.-H. Hong, C.-C. Su, C.-Y. Wang, and J.-S. Lai, “Field measurements and simulation of bridge scour depth variations during floods," Journal of Hydraulic Engineering, vol. 134, no. 6, pp. 810-821, 2008.

[24] N. L. Coleman, "Analyzing laboratory measurements of scour at cylindrical piers in sand beds," in Proceedings of the 14th IAHR World Congress, International Association of Hydraulic Research, Paris, France, 1971.

[25] S. C. Jain and E. E. Fischer, "Scour around bridge piers at high flow velocities," Journal of the Hydraulics Division, vol. 106, no. 11, pp. 1827-1842, 1980.

[26] Y. M. Chiew and B. W. Melville, "Local scour around bridge piers," Journal of Hydraulic Research, vol. 25, no. 1, pp. 15-26, 1987.

[27] E. V. Richardson and S. R. Davis, "Evaluating scour at bridges," in Hydraulic Engineering Circular No. 18 (HEC-18), Report No. FHWA-IP-90-17, Office of Technology Applications, Federal Highway Administration, US Department of Transportation, Washington, DC, USA, 3rd edition, 1995.

[28] D. M. Sheppard and W. Miller Jr., "Live-bed local pier scour experiments," Journal of Hydraulic Engineering, vol. 132, no. 7, pp. 635-642, 2006.

[29] M. Beg, "Predictive competence of existing bridge pier scour depth predictors," European International Journal of Science and Technology, vol. 2, no. 1, pp. 161-178, 2013.

[30] S. C. Inglis, Maximum Depth of Scour at Heads of Guide Banks and Groynes, Pier Noses, and Downstream of Bridges-The Behavior and Control of Rivers and Canals, Indian Waterways Experimental Station, Poona, India, 1949.

[31] M. Ahmad, "Experiments on design and behavior of spur dikes," in Proceedings of the Minnesota International Hydraulic Convention, pp. 149-159, St. Anthony Falls Hydraulics Laboratory, Minneapolis, Minn, USA, 1953.

[32] S. V. Chitale, "Scour at bridge crossings," Transactions of the American Society of Civil Engineers, vol. 127, no. 1, pp. 191-196, 1962.

[33] S. Hancu, "Sur le calcul des affouillementslocauxdans la zone des piles du pont," in Proceedings of the 14th Congress of the International Association for Hydraulic Research, pp. 299-305, Paris, France, 1971 (French).

[34] R. Gaudio, C. Grimaldi, A. Tafarojnoruz, and F. Calomino, "Comparison of formulae for the prediction of scour depth at piers," in Proceedings of the 1st IAHR European Division Congress, Heriot-Watt University, Edinburgh, UK, May 2010.

[35] U. C. Kothyari, R. J. Garde, and K. G. Ranga Raju, "Temporal variation of scour around circular bridge piers," Journal of Hydraulic Engineering ASCE, vol. 118, no. 8, pp. 1091-1106, 1992.

[36] E. V. Richardson and S. R. Davis, "Evaluating scour at bridges," Hydraulic Engineering Circular no. 18 (HEC-18), Report FHWA NHI 01-001, US Department of Transportation, Federal Highway Administration, Washington, DC, USA, 2001.

[37] E. M. Laursen and A. Toch, "Scour around bridge piers and abutments," Bulletin No. 4, Iowa Highway Research Board, Ames, Iowa, USA, 1956.

[38] C. R. Neill, Guide to Bridge Hydraulics, Roads and Transportation Association of Canada, University of Toronto Press, Toronto, Canada, 1973.

[39] A. Shields, Anwendung der aehnlichkeitsmechanik und der turbulenzforschung auf die geschiebebewegung [Ph.D. thesis], Preussischen Versuchsanstalt für Wasserbau, Berlin, Germany, 1936(German).

[40] J. A. Roberson and C. T. Crowe, Engineering Fluid Mechanics, Houghton Mifflin, Boston, Mass, USA, 3rd edition, 1985.

[41] D. B. Simon and F. Senturk, Sediment Transport Technology, Water Resources Publications, Littleton, Colo, USA, 1976.

[42] T. J. Clover, Pocket Ref, Sequoia Publishing, 1995.

[43] W. H. Graf and I. Istiarto, "Flow pattern in the scour hole around a cylinder," Journal of Hydraulic Research, vol. 40, no. 1, pp. 1320, 2002.

[44] B. W. Melville and Y.-M. Chiew, "Time scale for local scour at bridge piers," Journal of Hydraulic Engineering, vol. 125, no. 1, pp. 59-65, 1999.

[45] H. Schlichting, Boundary Layer Theory, McGraw-Hill, New York, NY, USA, 1979.

[46] S.-C. Chen, H.-C. Chan, and T.-Y. Wu, "Experimental investigation of the flow field around a bridge pier with hooked collar," ICSE6-156, ICSE-6, Paris, France, 2012.

[47] G. Yu, S.-K. Tan, S.-Y. Lim, and M.-C. Ong, "Evaluation of the formulae of bridge Pier Scour depth using data of lightweight bed material," in Proceedings of the XXX IAHR Congress: Processes and Integrated Management, pp. 277-283, International Association of Hydraulic Engineering and Research, Thessaloniki, Greece, August 2003.

[48] D. Gao, G. L. Posada, and C. F. Nordin, "Pier scour equations used in the People's Republic of China," Tech. Rep. FHWASA-93-076, Federal Highway Administration, Washington, DC, USA, 1993. 

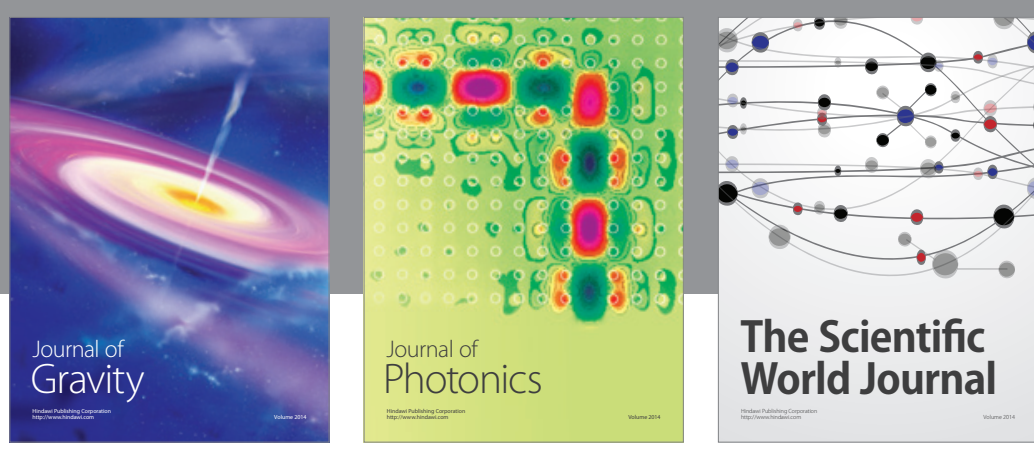

The Scientific World Journal
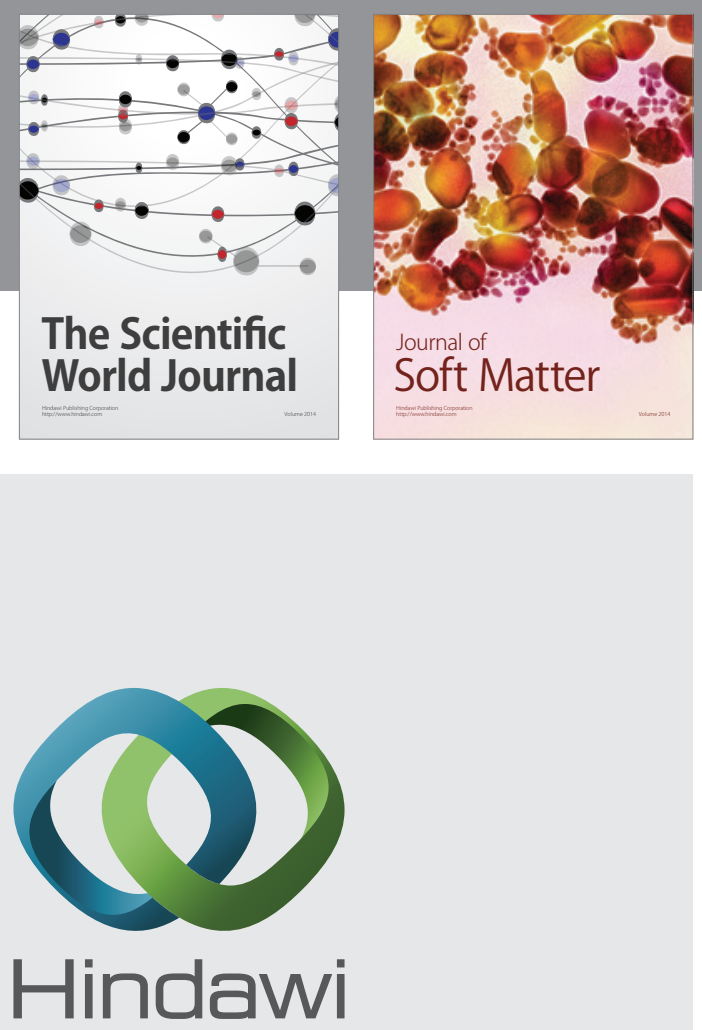

Submit your manuscripts at

http://www.hindawi.com

nternational Journal of

Statistical Mechanics
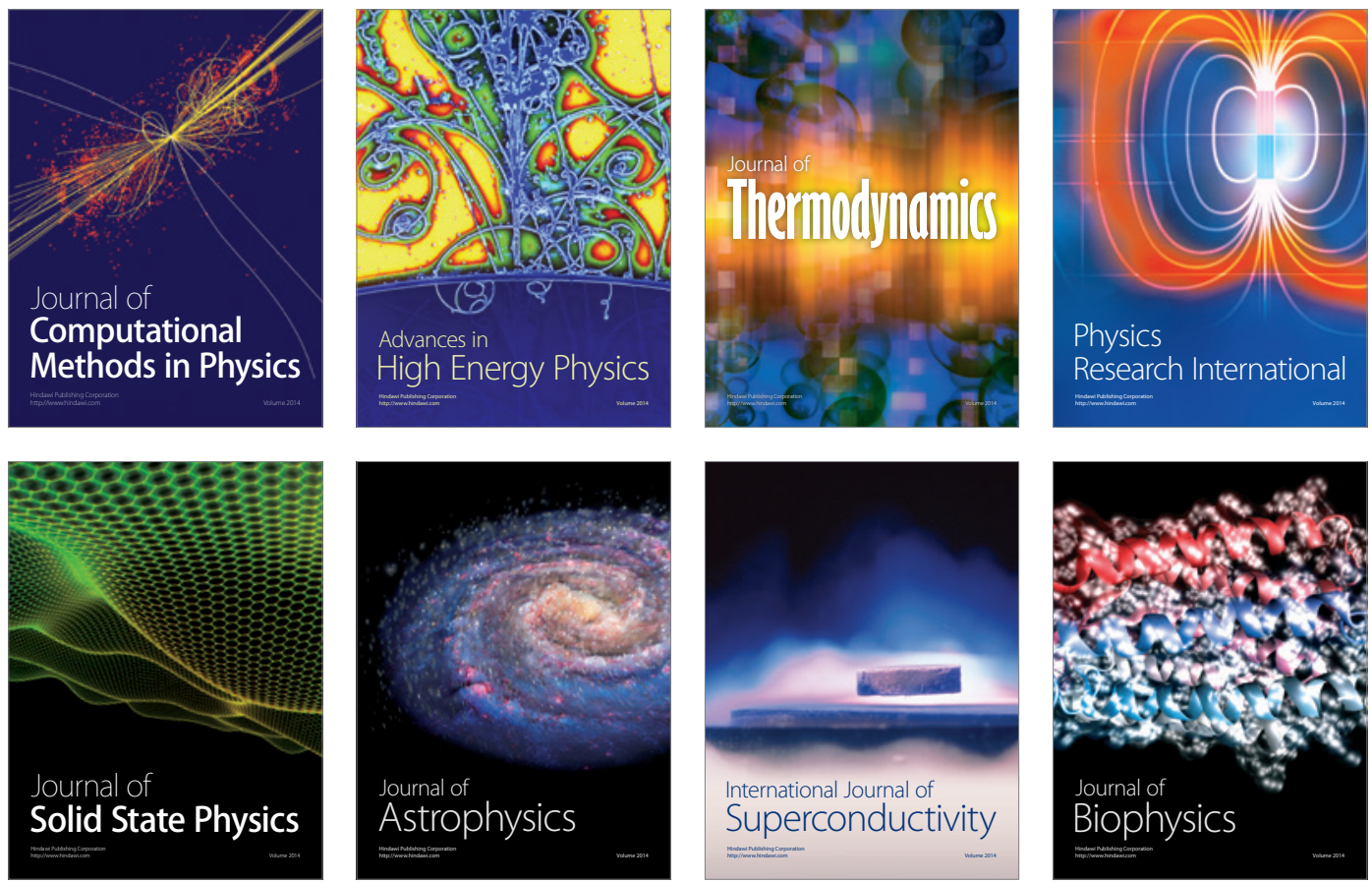
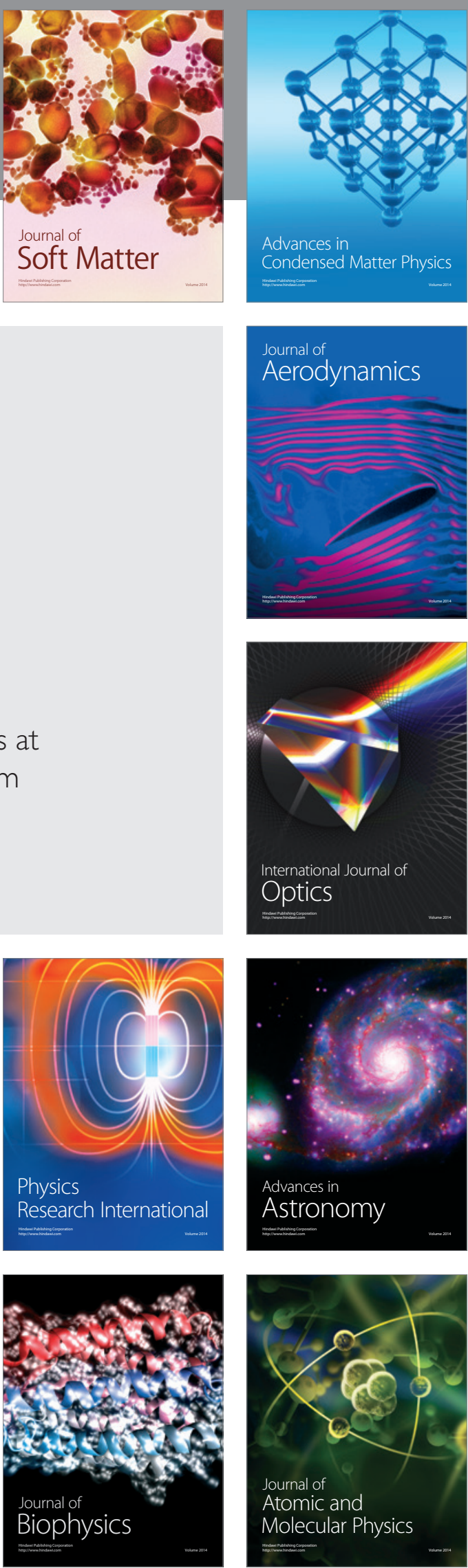